\title{
Fracturing of ductile anisotropic multilayers: influence of material strength
}

\author{
E. Gomez-Rivas ${ }^{1}$, A. Griera ${ }^{2}$, and M.-G. Llorens ${ }^{3}$ \\ ${ }^{1}$ Department of Geology and Petroleum Geology, University of Aberdeen, Aberdeen, Scotland, UK \\ ${ }^{2}$ Departament de Geologia, Universitat Autònoma de Barcelona, Barcelona, Spain \\ ${ }^{3}$ Department of Geosciences, Eberhard Karls University of Tübingen, Tübingen, Germany \\ Correspondence to: E. Gomez-Rivas (e.gomez-rivas@abdn.ac.uk)
}

Received: 31 December 2014 - Published in Solid Earth Discuss.: 29 January 2015

Revised: 10 April 2015 - Accepted: 20 April 2015 - Published: 19 May 2015

\begin{abstract}
Fractures in rocks deformed under dominant ductile conditions typically form simultaneously with viscous flow. Material strength plays a fundamental role during fracture development in such systems, since fracture propagation can be strongly reduced if the material accommodates most of the deformation by viscous flow. Additionally, the degree and nature of anisotropy can influence the orientation and type of resulting fractures. In this study, four plasticine multilayer models have been deformed under coaxial boundary conditions to investigate the influence of strength and anisotropy on the formation of fracture networks. The experiments were made of different mixtures and had two types of anisotropy: composite and composite-intrinsic. The transition from non-localised deformation to systems where fracture networks control deformation accommodation is determined by the ability of the material to dissipate the external work and relax the elastic strain during loading either by viscous flow or by coeval flow and failure. Tension cracks grow in experiments with composite anisotropy, giving rise to a network of shear fractures when they collapse and coalesce with progressive deformation. The presence of an additional intrinsic anisotropy enhances the direct nucleation of shear fractures, the propagation and final length of which depend on the rigidity of the medium. Material strength increases the fracture maximum displacement $\left(d_{\max }\right)$ to fracture length $(L)$ ratio, and the resulting values are significantly higher than those from fractures in elastic-brittle rocks. This can be related to the low propagation rates of fractures in rocks undergoing ductile deformation.
\end{abstract}

\section{Introduction}

The deformation behaviour of Earth's crust rocks is often seen as a transition from frictional and elastic-brittle behaviour at shallow depths to ductile crystal-plastic flow at deeper levels. The change from brittle and discontinuous deformation (i.e. fracture-dominated) to ductile and continuous deformation (i.e. flow-dominated) is known as the brittleto-ductile transition and is typically characterised by systems in which displacement is accommodated by networks of shear zones where brittle and ductile deformation coexist and compete (e.g. Paterson, 1978; Passchier, 1984; Hobbs et al., 1986; Mancktelow, 2008). It is assumed that an increase in depth progressively reduces pressure-dependent plasticity and increases viscous flow, which is mainly controlled by strain rate and temperature. However, field observations and experiments suggest that coeval fracturing and rock flow are not restricted to a certain zone in the middle crust but can affect rocks at a wide range of depths and deformation conditions from the Earth's surface to the upper mantle (e.g. Simpson, 1985; Pennacchioni and Cesare, 1997; Guermani and Pennacchioni, 1998; Passchier, 2001; Exner et al., 2004; Kocher and Mancktelow, 2005, 2006; Mancktelow, 2006; 2009). Moreover, brittle fractures can be precursors of ductile shear zones in certain cases (e.g. Segall and Simpson, 1986; Pennacchioni, 2005; Mancktelow and Pennacchioni, 2005; Pennacchioni and Mancktelow, 2007; Fusseis et al., 2006; Misra et al., 2009). It is therefore of crucial importance to recognise the main parameters controlling systems in which brittle and ductile deformation coexist. We understand brittle behaviour here as deformation showing loss of cohesion 

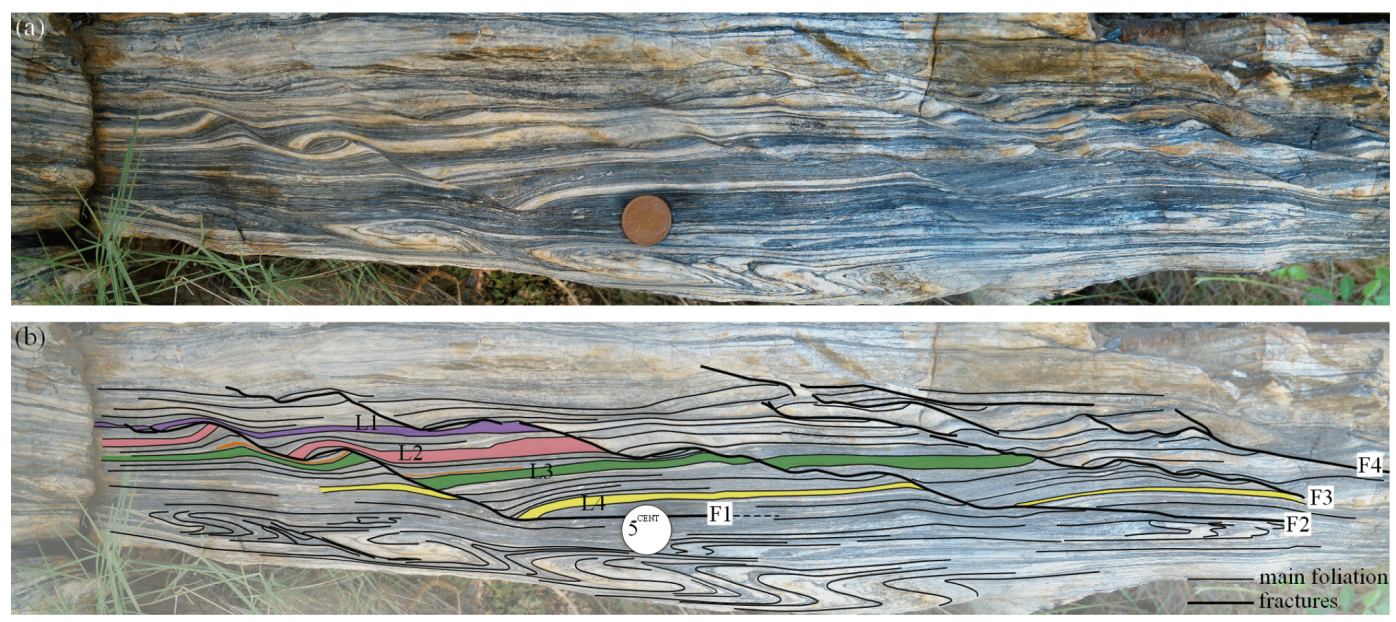

Figure 1. Examples of brittle deformation localisation in a ductile dominant system. (a) small-scale shear fractures (F1 to F4) with flat/ramp segments and roll-over geometries in deformed banded quartzites of the Rabassers outcrop, at Cap de Creus (E Pyrenees, Spain) (GomezRivas et al., 2007); (b) the interpreted structures. Fracture planes are smooth. Antithetic, synthetic and double-sense drag folds can be observed. Note that same layers at both sides of fractures do not present the same drag fold pattern. Displacements along fault surfaces are not constant and do not show an elliptical distribution, as expected for an isolated fracture. Maximum displacement-length relationships $\left(d_{\max } / L\right)$ range between 0.10 and 0.15 . These fractures are interpreted as formed by segment linkage and growth during coetaneous brittle and ductile deformation. Fracture offsets of reference layers are $0 \mathrm{~cm}(\mathrm{~L} 1), 3.5-3.8 \mathrm{~cm}$ (L2), 2.5-3.0 cm (L3) and 3.3-3.7 cm (L4). This view is perpendicular to the foliation and fracture planes. Anisotropy of this rock is a consequence of grain size differences between dark and white layers and preferred orientation of phyllosilicates. The diameter of the Eur 0.05 coin is $21 \mathrm{~mm}$.

along discrete surfaces, and we therefore assume that it results in strongly localised systems. In a different manner, we consider that ductile strain can be localised or distributed. Ductile localisation is characterised by zones of localised deformation with continuous variations of strain across their width (i.e. without discontinuity) and without loss of cohesion (e.g. Twiss and Moores, 1992). In this contribution, the term ductile is not associated with any particular constitutive relationship (e.g. viscous or plastic behaviour). We refer here to viscous deformation when stress is dependent on the strain rate. Figure 1 shows an illustrative example of the interaction of brittle and ductile deformation in a deformed quartzite (Cap de Creus, eastern Pyrenees, northern Spain) in a greenschist environment (Gomez-Rivas et al., 2007). Layers, defined by grain-size variations and preferential orientation of phyllosilicates, can be used as markers to track the displacement field. They show that these rocks coevally fractured and flowed, as evidenced by the presence of isoclinal folds outside fracture zones and drag folds associated with small-scale faults. The resulting fractures present relatively high values of maximum displacement $\left(d_{\max }\right)$ to length $(L)$ ratios, with strong gradients along them. It is a common observation that $d_{\max } / L$ ratios are significantly higher in systems dominated by ductile deformation (on the order of $\sim 10^{-1}$, e.g. GomezRivas and Griera, 2011; Grasemann et al., 2011) than in brittle media (which range from $\sim 10^{-2}$ to $\sim 10^{-4}$ ) (e.g. Walsh and Watterson, 1987; Kim and Sanderson, 2005). This can be explained by the low propagation rate and rotation of fractures in ductile media compared to those in elastic-brittle rocks (e.g. Exner et al., 2004; Kocher and Mancktelow, 2005; Pennacchioni and Mancktelow, 2007).

The formation of brittle fractures in elastoplastic materials is a relatively well-known process (e.g. Mandl, 2000, and references therein). However, there are still many open questions about how fractures and shear bands form and evolve in rocks deformed by dominant viscous flow. Conceptually, brittle fractures will normally develop in a ductile medium when viscous flow is not able to relax the loading stress, therefore reaching the strength limit of the material. Under these conditions, fracture propagation has to be studied as a time-independent process, because plastic strain work at crack tips is significantly increased during propagation and can result in a reduction of fracture propagation rates (e.g. Perez, 2004). A number of factors determine the characteristics of the resulting fracture network in such complex coupled systems (e.g. amount of fractures, formation mechanisms, orientations, type, connectivity, displacement). One of these factors is material stiffness, which defines how rigid a material is and can therefore determine the relative ratio of loading rate to the rate of stress relaxation by viscous flow, which at the end would control material strength in a ductile system (i.e. how the rock resists deformation). Indeed, viscosity defines the rock's resistance to deformation by shear and tensile stresses and can therefore control the brittle-to-ductile transition. Another relevant factor is the degree of anisotropy, which can induce a directional dependence of the resistance to deform. Transverse anisotropy is a very common type of rock heterogeneity and can arise from 


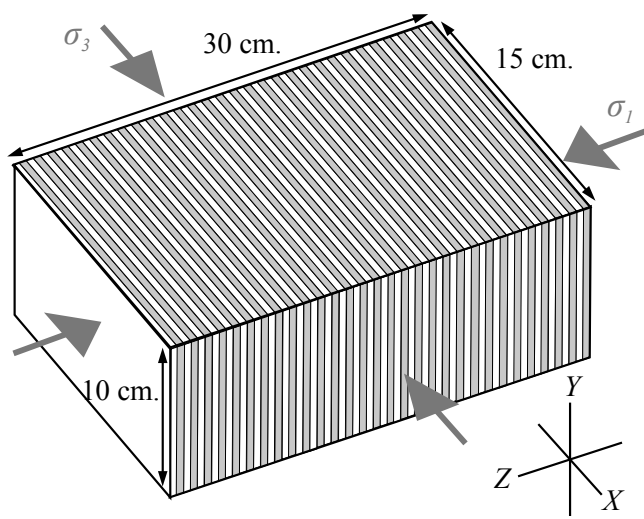

Figure 2. Sketch of a multilayer experiment. The arrows indicate the direction of the principal stresses applied by the deformation apparatus. The initial layer thickness was $\sim 4-5 \mathrm{~mm}$. After GomezRivas and Griera (2011).

the stacking of layers with different properties (i.e. composite anisotropy; Treagus, 1997) and/or from the presence of preferentially oriented planar minerals (i.e. intrinsic anisotropy; e.g. Griera et al., 2013).

This contribution presents an experimental study of the influence of material strength and the degree and type of anisotropy on the formation of brittle fractures in ductile multilayers under low effective confinement and plane strain conditions. Plasticine multilayers with different mechanical properties and anisotropies have been coaxially deformed at a constant strain rate to visualise the transition from nonlocalising systems to models where deformation is strongly localised along a few large fractures. Layers in these experiments are oriented parallel to the extension direction and perpendicular to the maximum compression. We aim to address cases where effective confining pressure is relatively low, like ductile rocks at shallow depths (e.g. clays, salt bodies, etc.) or middle- to lower-crust rocks with high fluid pressures or subjected to local effective tensional stress (e.g. Fagereng, 2013). We aim to (1) analyse the influence of material strength on the transition from non-localising to strongly localised systems using the same deformation conditions and very similar analogue materials, (2) address the role of different types of transverse anisotropy (composite and composite-intrinsic) on the degree of localisation and developed structures, (3) understand how coeval ductile-brittle deformation is visualised in terms of stress-strain relations and (4) capture the key factors controlling the style and characteristics of the resulting structures (tension and shear fractures, pinch-and-swell) and how they evolve towards welldeveloped fracture networks with different properties (orientations, displacement-length ratios, etc.). In order to provide proper dynamic scaling and define the mechanical reference framework, the rheology of the analogue materials was characterised prior to experiments with uniaxial compression and relaxation tests.

\section{Materials and methods}

\subsection{Deformation apparatus}

A strain rate and temperature-controlled apparatus $(\mathrm{BCN}$ stage; Carreras et al., 2000) was used to deform the plasticine models. The prototype is based at the Universitat Autònoma de Barcelona (Spain) and can apply deformations from pure to simple shear $(0<\mathrm{Wk}<1)$ at variable temperatures. This apparatus has been used for several analogue modelling studies (Druguet and Carreras, 2006; Bons et al., 2008; Druguet and Castaño, 2010; Gomez-Rivas, 2008; Gomez-Rivas and Griera, 2009, 2011, 2012).

\subsection{Experimental setup and deformation conditions}

Plasticine is an ideal analogue of rocks undergoing coeval ductile and brittle deformation, because it can flow and also fracture at the same time depending on its composition and deformation conditions (temperature, strain rate, boundary conditions). It therefore presents elastoviscoplastic behaviour. Two kinds of commercial plasticine were utilised in this study. They were sold under the trademarks OCLUPLAST and JOVI, both manufactured in Barcelona (Spain). Using them as a base, four different mixtures were created in order to build four models: type A (white and purple OCLUPLAST pure plasticine), type B (white and purple OCLUPLAST plasticine mixed with $10 \%$ paper flakes), type C (white and green JOVI pure plasticine) and type D (blue and red JOVI plasticine mixed with $10 \%$ paper flakes). Please note that the type A plasticine was the same material used for the experiments of Gomez-Rivas and Griera (2011, 2012). Flakes were made of differently coloured paper and had a maximum size of $\sim 2 \mathrm{~mm}$ and a density of $80 \mathrm{~g} \mathrm{~m}^{-2}$. The density of these plasticines is $\sim 1100 \mathrm{~kg} \mathrm{~m}^{-3}$. The models were created by stacking layers ( $\sim 4.25$ to $\sim 4.50 \mathrm{~mm}$ thick) of alternating colours, oriented perpendicular to the $Z$ direction (Fig. 2). This thickness could vary up to $\pm 0.5 \mathrm{~mm}$ for models with paper flakes. Two consecutive layers of the same (intermediate) colour were inserted twice in each model (at $Z=10 \mathrm{~cm}$ and $Z=20 \mathrm{~cm}$ ) in order to have reference markers for the quick identification of structures and other layers. Materials were mixed by hand at room temperature and then flattened with an adjustable hand rolling mill for engraving art $(\sim 50 \mathrm{~cm}$ long and with a diameter of $\sim 15 \mathrm{~cm})$. In this way, paper flakes were preferentially oriented parallel to layers and therefore perpendicular to the compression direction $Z$. This procedure also avoided the presence of air bubbles within the models.

Transverse anisotropy in all models was defined by the stacking of beds, which created a composite layering. Additionally, experiments containing paper flakes (B and D) also presented an intrinsic anisotropy defined by their preferred orientation. It is important to note that these flakes were inserted in order to increase the degree of anisotropy and do not 
try to simulate the role of individual minerals in rocks. Each model had an initial size of $30 \times 15 \times 10 \mathrm{~cm}$ and was compressed in the $Z$ direction and extended in the $X$ direction, while the $Y$ direction remained constant using a reinforced transparent glass. Strain rate and temperature were kept constant at $2 \times 10^{-5} \mathrm{~s}^{-1}$ and $26^{\circ} \mathrm{C}$ respectively. The samples were deformed until a bulk finite strain ratio of $R X / Z \sim 4$ (i.e. $\sim 50 \%$ shortening). Stress was recorded using gauges parallel to $X$ and $Z$. Digital pictures of the upper surface $(X-Z$ plane) were taken every $1 \%$ shortening. Frictional effects were minimised by lubricating the press boundaries with Vaseline and the top surface with glycerine. Each model was biaxially compressed during $24 \mathrm{~h}$ at $\sim 10 \mathrm{kPa}$ prior to deformation in order to bond layers and avoid further interlayer slipping.

A $100 \mathrm{~cm}^{2}$ area at the centre of each model was used for acquiring fracture data and observations, thus avoiding boundary effects such as friction with walls. The following parameters were systematically measured on all fractures at $10 \%$ shortening intervals: fracture length $(L)$, angle between fracture and the $Z$ axis $(\delta)$ and cumulative fracture displacement $\left(d_{\max }\right)$. In order to minimise personal bias effects while collecting data, the two first authors independently acquired measurements and the root mean square deviation normalised to mean values was systematically calculated for each parameter.

The degree of localisation was macroscopically estimated with a strain localisation factor $\left(I_{\mathrm{loc}}\right)$. We defined this parameter as the ratio of the maximum to the minimum shortening measured using reference layers for each model (see Sect. 3), which were used as normal shortening markers. Homogeneous deformation would result in $I_{\mathrm{loc}}=1$.

\subsection{Mechanical properties of the experimental materials}

Prior to carrying out the experiments, the mechanical properties of each analogue material were characterised with uniaxial compression and relaxation tests at variable strain rates and temperatures. A total of 30 tests were performed by deforming $10 \mathrm{~cm}$ cubes up to a minimum $20 \%$ shortening at variable strain rates, using the same deformation apparatus and procedure as for the final experiments. The cubes were shaped using a wooden plate to form the six faces and then cut with a saw. The methods and equations for these tests are described in detail in Gomez-Rivas and Griera (2011) and are based on the studies of McClay (1976), Weijermars and Schmeling (1986), Mancktelow (1988), Ranalli (1995), Schöpfer and Zulauf (2002) and Zulauf and Zulauf (2004).

The conditions at which the tests were run, and the parameters resulting from them are summarised in Tables 1 and 2 and Figs. 3 and 4. Parameters, including volumetric strain, were calculated at $10 \%$ shortening. It is important to note that the samples did not fracture during uniaxial compression. The results indicate that these mixtures behave as non- linear elastoviscous materials with stress exponents ranging from $n \sim 3-4$ for pure plasticine (types A and C) to $n \sim 4.5-$ 5 for mixtures containing plasticine and paper flakes (types $\mathrm{B}$ and D). The correlation coefficients $\left(R^{2}\right)$ calculated from the log diagrams of strain rate vs. stress range between 0.73 and 0.98 . The reason why stress exponents are higher in mixtures containing paper flakes than in those composed of pure plasticine is because flakes produce an increase of strain partitioning and heterogeneities of the flow field. A marked strain hardening can be identified form strain-stress curves for most of the tests (Fig. 3). However, the amount of shortening reached during these tests was not high enough to produce macroscopic failure. Clear yield stresses can be detected in most of the tests made of OCLU-PLAST and in some made of JOVI plasticine. However, not all tests present yield stress, especially those with a higher viscoelastic response (Fig. 3f). The viscosities of the mixtures made of JOVI plasticine $(\mathrm{C}, \mathrm{D})$ are considerably higher than those of OCLU-PLAST (A, B). Adding paper flakes to plasticine makes the material stiffer and increases the non-linearity behaviour of the mixture. The addition of dye (purple or green) to plasticine makes it slightly softer and more non-linear than the white one, although its rheology does not significantly change. Strain vs. effective viscosity curves reveal a marked strain-rate softening (Fig. 4). These two types of plasticine have an effective viscosity between $\sim 0.6 \times 10^{9}$ and $\sim 3 \times 10^{9} \mathrm{Pas}$ at low strain rates and thus behave in a similar way than other kinds of plasticine used by other authors (see Fig. 4, references included in the figure). Volumetric strain values (Table 1) indicate that these mixtures loose between $\sim 1$ and $\sim 6 \%$ of their volume at $10 \%$ shortening. Mixtures composed of OCLU-PLAST plasticine undergo more volumetric strain when paper flakes are inserted. On the contrary, mixtures made of JOVI plasticine present a similar volumetric strain regardless of whether they contain paper flakes or not. A dependence of volumetric strain on strain rate is not observed.

Relaxation tests (i.e. stress evolution under constant strain) revealed that the estimated elastic shear modulus $(G)$ ranges between $2.4 \times 10^{6}$ and $4.3 \times 10^{6} \mathrm{~Pa}$ for mixtures made of the softer plasticine (types A and B) and between $8.1 \times 10^{6}$ and $1.2 \times 10^{7} \mathrm{~Pa}$ for mixtures made of the harder plasticine (types $\mathrm{C}$ and D) (Table 2). The Deborah number (De) (Reiner, 1964) is a non-dimensional factor that defines how fluid a material is, and it is equivalent to the ratio of the time of relaxation (Maxwell time, $\tau_{\mathrm{m}}$ ) and the time of observation (strain rate, $\dot{\varepsilon}$ ). Estimated $D e$ values (between $3.8 \times 10^{-3}$ and $5.8 \times 10^{-3}$; Table 2 ) indicate that our experimental materials have the typical relaxation behaviour of a viscoelastic solid (e.g. Poliakov et al, 1993).

Models $\mathrm{A}$ and $\mathrm{C}$ have a relative low degree of anisotropy because of the low viscosity contrast between alternating layers. On the contrary, models B and D are significantly more anisotropic, since they contain preferentially oriented paper flakes. Gomez-Rivas and Griera (2009) estimated a degree 
Table 1. Properties calculated from compression tests for the different mixtures used as rock analogues. The values of axial stress, dynamic effective viscosity, stress exponent and material constant were calculated for $10 \%$ shortening.

\begin{tabular}{|c|c|c|c|c|c|c|c|}
\hline $\begin{array}{l}\text { Type } \\
\text { of mixture }\end{array}$ & Composition & $\begin{array}{r}\text { Strain } \\
\text { rate } \\
(\dot{\varepsilon})\left[\mathrm{s}^{-1}\right]\end{array}$ & $\begin{array}{r}\text { Axial } \\
\text { stress } \\
(\sigma)[\mathrm{Pa}]\end{array}$ & $\begin{array}{l}\text { Effective } \\
\text { viscosity } \\
\text { ( } \eta \text { ) }[\mathrm{Pa} \mathrm{s}]\end{array}$ & $\begin{array}{r}\text { Stress } \\
\text { exponent } \\
(n)\end{array}$ & $\begin{array}{r}\text { Material } \\
\text { constant } \\
\text { (C) }\left[\mathrm{Pa}^{-n} \mathrm{~s}^{-1}\right]\end{array}$ & $\begin{array}{r}\text { Volumetric } \\
\text { strain \% } \\
(\mathrm{d} V / V)\end{array}$ \\
\hline A white & $\begin{array}{l}\text { OCLU-PLAST } \\
\text { white } \\
\text { plasticine }\end{array}$ & $\begin{array}{l}1.8 \times 10^{-5} \\
5.5 \times 10^{-5} \\
1.0 \times 10^{-4} \\
2.6 \times 10^{-4}\end{array}$ & $\begin{array}{l}2.4 \times 10^{4} \\
3.6 \times 10^{4} \\
3.2 \times 10^{4} \\
4.8 \times 10^{4}\end{array}$ & $\begin{array}{l}6.1 \times 10^{8} \\
3.0 \times 10^{8} \\
1.6 \times 10^{8} \\
4.8 \times 10^{7}\end{array}$ & 3.9 & $\begin{array}{l}1.8 \times 10^{-22} \\
1.3 \times 10^{-22} \\
2.7 \times 10^{-22} \\
2.0 \times 10^{-22}\end{array}$ & $\begin{array}{l}-2.4 \\
-2.3 \\
-2.6 \\
-1.0\end{array}$ \\
\hline A coloured & $\begin{array}{l}\text { OCLU-PLAST } \\
\text { coloured } \\
\text { plasticine }\end{array}$ & $\begin{array}{l}1.9 \times 10^{-5} \\
5.5 \times 10^{-5} \\
1.0 \times 10^{-4} \\
2.5 \times 10^{-4}\end{array}$ & $\begin{array}{l}2.3 \times 10^{4} \\
2.6 \times 10^{4} \\
3.8 \times 10^{4} \\
3.3 \times 10^{4}\end{array}$ & $\begin{array}{l}5.8 \times 10^{8} \\
2.1 \times 10^{8} \\
1.9 \times 10^{8} \\
3.3 \times 10^{7}\end{array}$ & 4.1 & $\begin{array}{l}3.5 \times 10^{-23} \\
7.1 \times 10^{-23} \\
1.5 \times 10^{-23} \\
2.7 \times 10^{-22}\end{array}$ & $\begin{array}{l}-2.0 \\
-2.5 \\
-1.2 \\
-2.4\end{array}$ \\
\hline B white & $\begin{array}{l}\text { OCLU-PLAST } \\
\text { white } \\
\text { plasticine } \\
+10 \% \text { flakes }\end{array}$ & $\begin{array}{l}1.8 \times 10^{-5} \\
5.4 \times 10^{-5} \\
8.8 \times 10^{-5} \\
2.5 \times 10^{-4}\end{array}$ & $\begin{array}{l}4.5 \times 10^{4} \\
3.6 \times 10^{4} \\
4.6 \times 10^{4} \\
4.4 \times 10^{4}\end{array}$ & $\begin{array}{l}1.1 \times 10^{9} \\
3.0 \times 10^{8} \\
2.3 \times 10^{8} \\
4.4 \times 10^{7}\end{array}$ & 5.3 & $\begin{array}{l}5.8 \times 10^{-30} \\
4.9 \times 10^{-29} \\
2.6 \times 10^{-29} \\
1.9 \times 10^{-27}\end{array}$ & $\begin{array}{l}-4.6 \\
-3.7 \\
-4.1 \\
-3.9\end{array}$ \\
\hline $\mathrm{C}$ white & $\begin{array}{l}\text { JOVI white } \\
\text { plasticine }\end{array}$ & $\begin{array}{l}1.9 \times 10^{-5} \\
5.5 \times 10^{-5} \\
8.9 \times 10^{-5} \\
2.1 \times 10^{-4}\end{array}$ & $\begin{array}{l}6.9 \times 10^{4} \\
1.0 \times 10^{5} \\
1.0 \times 10^{5} \\
9.3 \times 10^{4}\end{array}$ & $\begin{array}{l}1.7 \times 10^{9} \\
8.4 \times 10^{8} \\
5.2 \times 10^{8} \\
9.3 \times 10^{7}\end{array}$ & 3.3 & $\begin{array}{l}2.2 \times 10^{-21} \\
2.3 \times 10^{-21} \\
3.6 \times 10^{-21} \\
4.5 \times 10^{-19}\end{array}$ & $\begin{array}{l}-5.8 \\
-3.5 \\
-2.4 \\
-5.1\end{array}$ \\
\hline $\mathrm{C}$ col & $\begin{array}{l}\text { JOVI } \\
\text { coloured } \\
\text { plasticine }\end{array}$ & $\begin{array}{l}1.8 \times 10^{-5} \\
5.3 \times 10^{-5} \\
9.2 \times 10^{-5} \\
2.4 \times 10^{-4}\end{array}$ & $\begin{array}{l}9.9 \times 10^{4} \\
7.5 \times 10^{4} \\
8.1 \times 10^{4} \\
1.1 \times 10^{5}\end{array}$ & $\begin{array}{l}2.5 \times 10^{9} \\
6.2 \times 10^{8} \\
4.0 \times 10^{8} \\
1.1 \times 10^{8}\end{array}$ & 3.9 & $\begin{array}{l}8.7 \times 10^{-25} \\
8.5 \times 10^{-24} \\
9.1 \times 10^{-24} \\
1.0 \times 10^{-22}\end{array}$ & $\begin{array}{l}-3.8 \\
-2.1 \\
-2.5 \\
-2.1\end{array}$ \\
\hline D white & $\begin{array}{l}\text { JOVI white } \\
\text { plasticine } \\
+10 \% \text { flakes }\end{array}$ & $\begin{array}{l}1.6 \times 10^{-5} \\
5.0 \times 10^{-5} \\
8.9 \times 10^{-5} \\
2.4 \times 10^{-4}\end{array}$ & $\begin{array}{l}1.4 \times 10^{5} \\
8.3 \times 10^{4} \\
1.2 \times 10^{5} \\
1.2 \times 10^{5}\end{array}$ & $\begin{array}{l}3.4 \times 10^{9} \\
6.9 \times 10^{8} \\
5.8 \times 10^{8} \\
1.2 \times 10^{8}\end{array}$ & 4.5 & $\begin{array}{l}2.7 \times 10^{-28} \\
5.9 \times 10^{-27} \\
1.7 \times 10^{-27} \\
7.0 \times 10^{-26}\end{array}$ & $\begin{array}{l}-2.4 \\
-3.5 \\
-2.1 \\
-4.0\end{array}$ \\
\hline
\end{tabular}

Table 2. Summary of material properties calculated with relaxation tests for the different mixtures used as rock analogues. Only tests deformed at similar strain rates than multilayer experiments are displayed. The values of elastic shear modulus $(G)$ and Deborah number (De) were calculated assuming a Maxwell body.

\begin{tabular}{llrrr}
\hline $\begin{array}{l}\text { Type } \\
\text { of mixture }\end{array}$ & Composition & $\begin{array}{r}\text { Strain } \\
\text { rate }(\dot{\varepsilon})\left[\mathrm{s}^{-1}\right]\end{array}$ & $\begin{array}{r}\text { Elastic shear } \\
\text { modulus }(G)[\mathrm{Pa}]\end{array}$ & $\begin{array}{r}\text { Deborah } \\
\text { number }\end{array}$ \\
\hline A white & OCLU-PLAST white plasticine & $1.8 \times 10^{-5}$ & $2.4 \times 10^{6}$ & $4.6 \times 10^{-3}$ \\
A coloured & OCLU-PLAST coloured plasticine & $1.9 \times 10^{-5}$ & $2.0 \times 10^{6}$ & $5.8 \times 10^{-3}$ \\
B white & OCLU-PLAST white plasticine + 10\% flakes & $1.8 \times 10^{-5}$ & $4.3 \times 10^{6}$ & $4.6 \times 10^{-3}$ \\
C white & JOVI white plasticine & $1.9 \times 10^{-5}$ & $1.1 \times 10^{7}$ & $3.9 \times 10^{-3}$ \\
C coloured & JOVI coloured plasticine & $1.8 \times 10^{-5}$ & $8.1 \times 10^{6}$ & $4.8 \times 10^{-3}$ \\
D white & JOVI white plasticine + 10\% flakes & $1.6 \times 10^{-5}$ & $1.2 \times 10^{7}$ & $3.8 \times 10^{-3}$ \\
\hline
\end{tabular}

of anisotropy of $\sim 6$ for experiments that used a very similar composition to type B.

\subsection{Model scaling}

The experiments presented in this study are scaled based on the geometrical and dynamic similarity of the observed deformation, following the methods described by Ramberg (1981). The normal stress ratio between model and nature is $\sigma^{*}=\rho^{*} g^{*} l^{*}$, where $\rho^{*}, g^{*}$ and $l^{*}$ are the model/nature ratios of density, gravity and length respectively. Since we address fracture formation at the mesoscale, we have considered a ratio of $1: 1$ between the experimental and natural 

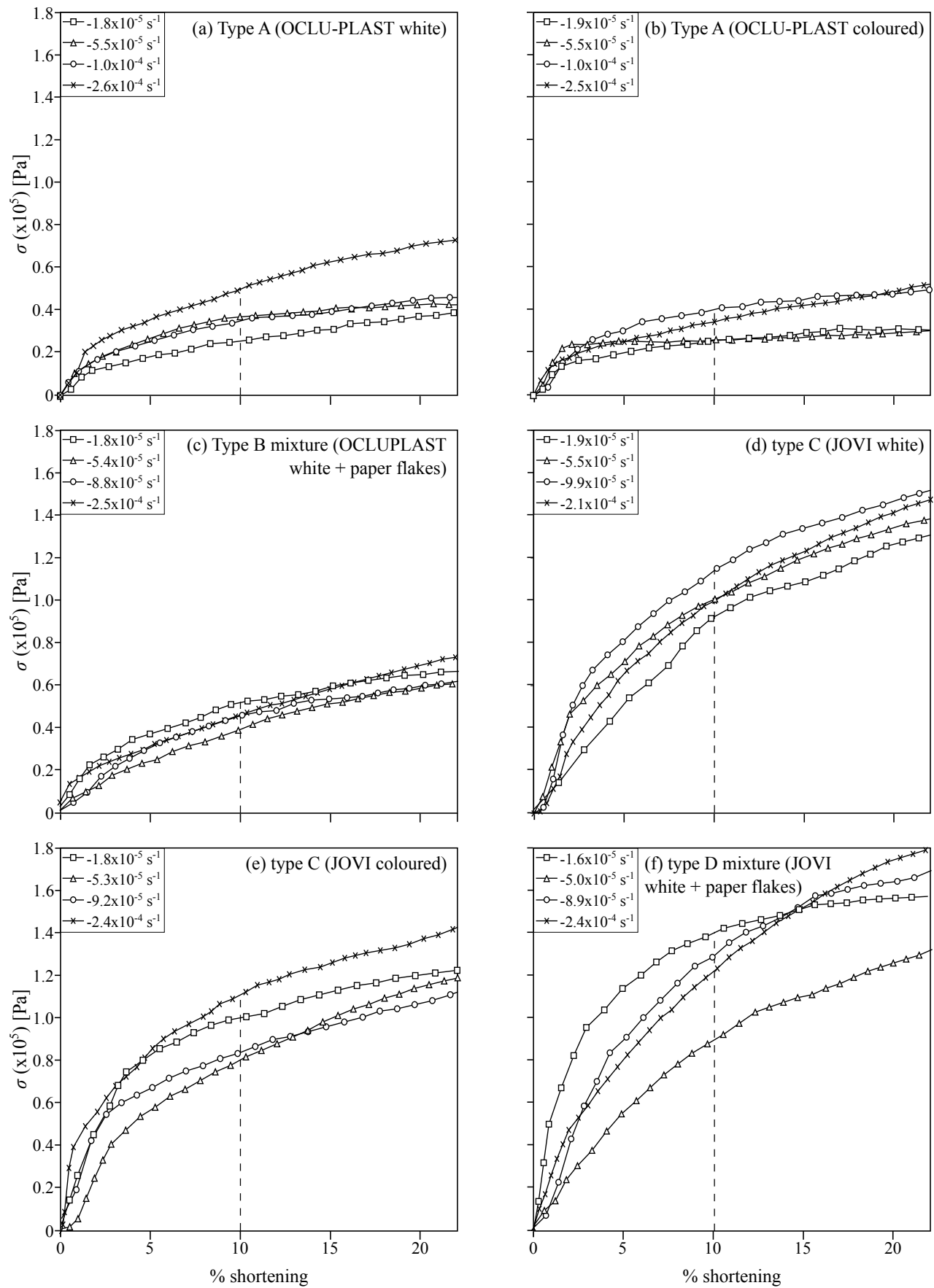

Figure 3. Stress vs. axial strain (expressed in \% shortening) curves for the materials used in this study at different strain rates. Dashed lines indicate the strain reference value used for comparison of material properties (10\% shortening).

scales in space. When the same gravity is assumed for both the experiments and nature, then the normal stress scaling ratio is only determined by the density ratio. As mentioned in Sect. 2.2 the models have a density of $\sim 1100 \mathrm{~kg} \mathrm{~m}^{-3}$. Therefore, the value of $\sigma^{*}$ is 0.41 when we consider that schists have an average density of $2700 \mathrm{~kg} \mathrm{~m}^{-3}$ (e.g. Smithson, 1970). The model/nature ratio of strain rate $\dot{\varepsilon}^{*}$ is $2 \times 10^{9}$, assuming a natural strain rate of $10^{-14} \mathrm{~s}^{-1}$ (e.g. Pfiffner and Ramsay, 1982). In this way, 1 experimental second (at $\dot{\varepsilon}=2 \times 10^{-5} \mathrm{~s}^{-1}$ ) is approximately equivalent to $\sim 60$ natural years. Therefore, the value of natural viscosity that would correspond to these experiments is expressed by

$\eta_{\text {nature }}=\frac{\eta_{\text {model }} \cdot \dot{\varepsilon}^{*}}{\sigma^{*}}$, 
Table 3. Values of strain rate and effective viscosity of mid-crustal rocks and the less and more viscous analogue materials used in this study (Types A and D mixtures respectively). The strain rate value for mid-crustal rocks was taken from Pfiffner and Ramsay (1982) and Weijermars (1997). The viscosity of schists was taken from Talbot (1999) and Davidson et al. (1994).

\begin{tabular}{llll}
\hline Material & Strain rate $(\dot{\varepsilon})\left[\mathrm{s}^{-1}\right]$ & $\begin{array}{l}\text { Deformation time } \\
\text { at } 50 \% \text { sh. }(t)[\mathrm{s}]\end{array}$ & Effective viscosity $\eta^{*}[\mathrm{Pas}]$ \\
\hline Mid-crustal rocks & $10^{-14}$ & $8.3 \times 10^{13}(\sim 2.6 \mathrm{Ma})$ & $\sim 10^{19}-10^{20}$ (schist at 500-700 ${ }^{\circ} \mathrm{C}$ ) \\
Type A mixture & $2 \times 10^{-5}$ & $3.4 \times 10^{4}$ & $6.1 \times 10^{8}$ (OCLU-PLAST plasticine) \\
Type A mixture & $10^{-4}$ & $6.2 \times 10^{3}$ & $1.6 \times 10^{8}$ (OCLU-PLAST plasticine) \\
Type D mixture & $2 \times 10^{-5}$ & $3.4 \times 10^{4}$ & $3.4 \times 10^{9}$ (JOVI plasticine + confetti) \\
\hline
\end{tabular}

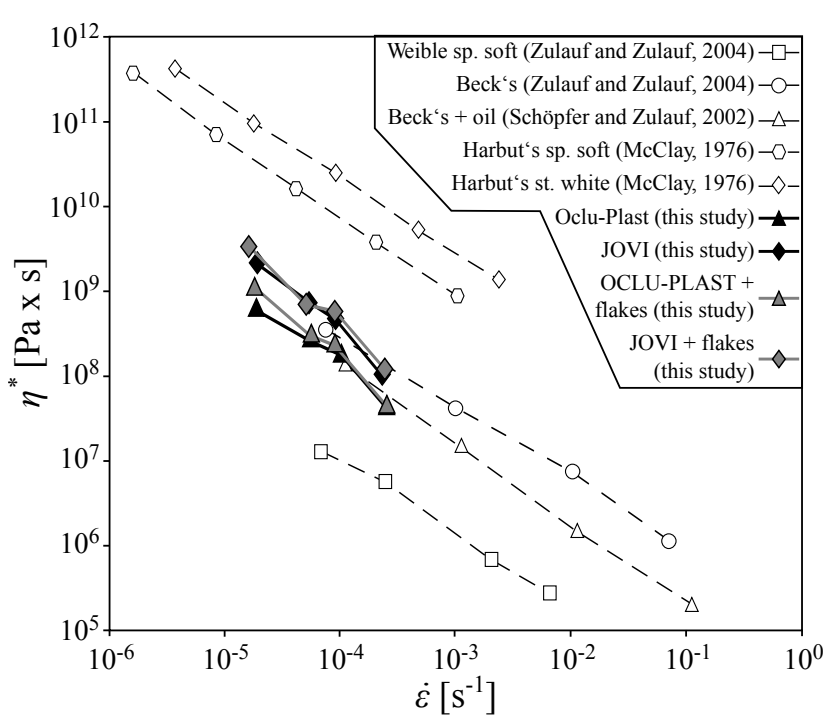

Figure 4. Log strain rate $(\dot{\varepsilon})$ vs. $\log$ effective dynamic viscosity $\left(\eta^{*}\right)$ comparing the mixtures used in this study with other kinds of commercially available plasticine used by other authors. Effective dynamic viscosity values were taken at $10 \%$ shortening. Modified from Gomez-Rivas and Griera (2011).

and therefore scaled natural viscosities of $3 \times 10^{18} \mathrm{Pas}$ and $1.7 \times 10^{19} \mathrm{~Pa}$ s would correspond to the softer (model A) and harder (model D) experiments respectively. Viscosity and strain rate values of experimental and natural materials are presented in Table 3 for their dynamic scaling. These values of scaled viscosities are slightly lower in magnitude than the estimated ones for schists in the middle crust, although within the published ranges $\left(\sim 10^{19}-10^{20}\right.$ Pa s: e.g. Talbot, 1999; Davidson et al., 1994) (Table 3).

\section{Experimental results}

The results of the four multilayer experiments indicate that the mechanical behaviour and the resulting deformation pattern are notably different depending on the material used (Fig. 5). There is a marked transition from a model in which deformation is almost homogeneously distributed (type A) to a system controlled by a few large shear fractures (type D). At the end of the experiments $(\sim 50 \%$ bulk shortening), model A accommodated deformation mainly by homogeneous flattening. Increasing the material strength resulted in a larger number of macroscopic fractures (models B, C and D), although the characteristics of the resulting fracture networks strongly varied between these three experiments. The stress-strain curves (Fig. 6) reveal that recorded stresses increased systematically from model A to model D. Deformation was mainly accommodated by homogeneous flow during the first deformation stages in all models. Such flow was associated with a stress increase. At about $10 \%$ shortening the yield stress was reached for the stiffer models (C and D) and progressively decreased in these experiments up to the end without reaching a clear steady state. The first macroscopic fractures were not visible until $\sim 15-18 \%$ shortening. In the softer models (A and B) a sharp yield stress was not identified, and stress progressively rose with strain until a steady state was reached. This steady state behaved slightly different in each experiment, as stress kept slowly growing in model B while it slightly decreased in model A.

The type of fractures and their orientations with respect to the deformation axes are also significantly different depending on the material (Figs. 7, 8, 9). Strain localisation and material embrittlement are enhanced when stiffness (or viscosity) is increased, and therefore the density and type of developed fractures strongly depend on how stiff the analogue material is. After $50 \%$ bulk shortening, deformation in experiment A was mainly accommodated by homogeneous flattening associated with viscous flow (Figs. 5, 8a-c). The estimated strain localisation factor was $I_{\text {loc }} \sim 1.04$ and normal shortening measured using the reference layers of Fig. 5 ranged between 50 and $52 \%$. Traction structures along layer interfaces associated with potential inter-layer slipping were not observed. Layers were thinned with increasing deforma- 

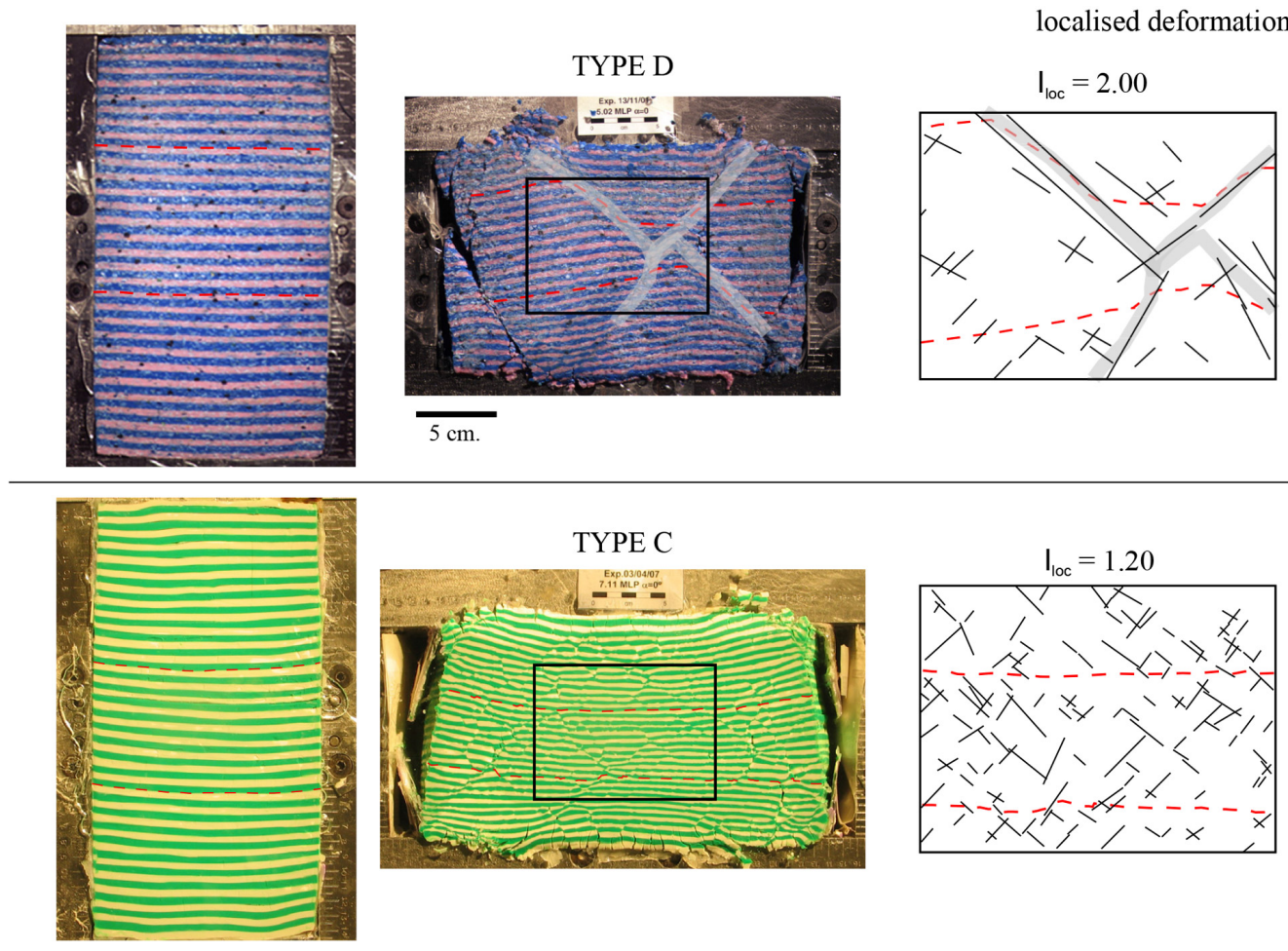

$\overline{5 \mathrm{~cm} .}$
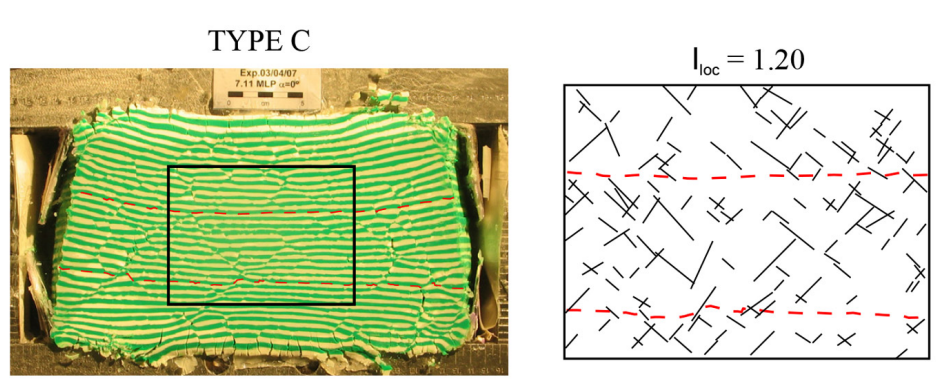

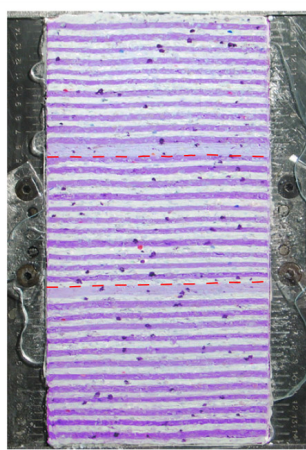

TYPE B
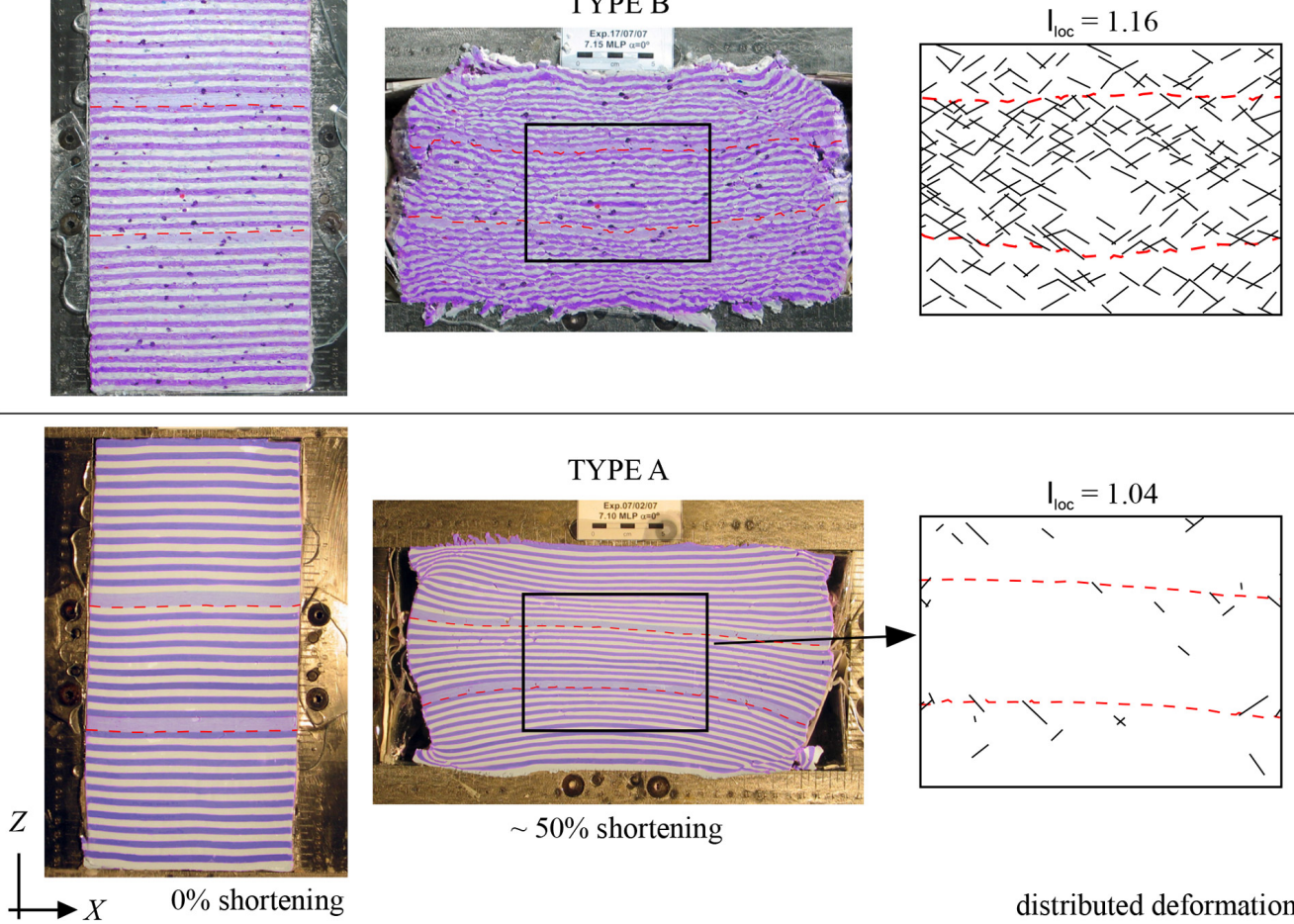

$\sim 50 \%$ shortening

distributed deformation

Figure 5. Photographs of the initial (0\% shortening) and final ( $~ 50 \%$ shortening) stages of the four multilayer models. Maps of analysed fracture networks are displayed on the right side. Red dashed lines indicate reference layers. Grey shadowed areas in type D model show the location of large fault zones. Only structures located in the central area of each model, indicated with a rectangle, are systematically studied. $I_{\text {loc }}$ is the localisation factor (see Sect. 2.2). The degree of localisation progressively increases from model A to model D and depends on the strength, effective viscosity and degree of anisotropy of the models. Marked differences between the resulting fracture networks can be clearly identified. 
Table 4. Compilation of shear-fracture data at shortening intervals of $20,30,40$ and $50 \%$. $\delta$ is the average shear-fracture orientation with respect to the $Z$ axis, measured in degrees. Fracture length $(L)$ and maximum displacement $\left(d_{\max }\right)$ of shear fractures are measured in cm. Standard deviations are in parentheses. $N$ and $N_{\text {tension }}$ indicate the total number of shear fractures and tension cracks respectively. Length $(L)$ values do not include data from tension cracks and refer to individual fracture segments. Fault zones composed of several segments are therefore longer than individual ones. The number of tension cracks for models B and D is not displayed, since cracks were too small to trace them accurately. Note that data corresponding to $50 \%$ shortening in model D were actually measured at $44 \%$ shortening, when this experiment finished.

\begin{tabular}{|c|c|c|c|c|c|c|c|c|}
\hline \multirow[t]{2}{*}{ Experiment } & \multicolumn{4}{|c|}{ Sinistral set of fractures } & \multicolumn{4}{|c|}{ Dextral set of fractures } \\
\hline & $20 \%$ & $30 \%$ & $40 \%$ & $50 \% \mathrm{sh}$. & $20 \%$ & $30 \%$ & $40 \%$ & $50 \%$ sh. \\
\hline \multicolumn{9}{|l|}{ Type A } \\
\hline$\delta$ & $-(-)$ & $45.3(2.3)$ & $47.0(3.2)$ & $49.1(4.1)$ & $-(-)$ & $-(-)$ & $41.1(3.5)$ & $48.8(4.5)$ \\
\hline$L$ & $-(-)$ & $0.41(0.17)$ & $0.68(0.31)$ & $0.69(0.33)$ & $-(-)$ & $-(-)$ & $0.53(0.10)$ & $0.67(0.28)$ \\
\hline$d_{\max }$ & $-(-)$ & $0.10(0.01)$ & $0.11(0.03)$ & $0.14(0.06)$ & $-(-)$ & $-(-)$ & $0.07(0.02)$ & $0.12(0.05)$ \\
\hline$N$ & 0 & 2 & 8 & 12 & 0 & 0 & 7 & 14 \\
\hline$N_{\text {tension }}$ & 2 & 6 & 7 & 7 & & & & \\
\hline \multicolumn{9}{|l|}{ Type B } \\
\hline$\delta$ & $48.5(3.4)$ & $52.0(4.2)$ & $53.7(6.1)$ & $55.4(6.9)$ & $49.7(3.5)$ & $52.3(4.0)$ & $55.0(4.3)$ & $57.6(5.5)$ \\
\hline$L$ & $0.67(0.07)$ & $0.75(0.10)$ & $0.77(0.13)$ & $0.85(0.16)$ & $0.71(0.07)$ & $0.75(0.10)$ & $0.85(0.20)$ & $0.92(0.29)$ \\
\hline$d_{\max }$ & $0.12(0.03)$ & $0.14(0.08)$ & $0.17(0.04)$ & $0.22(0.10)$ & $0.11(0.02)$ & $0.13(0.04)$ & $0.17(0.05)$ & $0.22(0.08)$ \\
\hline$N$ & 39 & 63 & 89 & 136 & 37 & 71 & 96 & 132 \\
\hline$N_{\text {tension }}$ & - & - & - & - & & & & \\
\hline \multicolumn{9}{|l|}{ Type C } \\
\hline$\delta$ & $21.3(-)$ & $31.9(7.0)$ & $37.0(7.8)$ & $42.3(7.2)$ & $32.3(3.2)$ & $36.9(6.3)$ & $44.6(5.4)$ & 49.5 (6.2) \\
\hline$L$ & $0.78(-)$ & $0.74(0.29)$ & $0.79(0.31)$ & $0.82(0.41)$ & $0.56(0.03)$ & $0.61(0.17)$ & $0.78(0.32)$ & $0.82(0.37)$ \\
\hline$d_{\max }$ & $0.12(-)$ & $0.12(0.06)$ & $0.15(0.07)$ & $0.18(0.09)$ & $0.07(0.01)$ & $0.11(0.03)$ & $0.19(0.10)$ & $0.20(0.10)$ \\
\hline$N$ & 1 & 17 & 41 & 72 & 3 & 17 & 40 & 74 \\
\hline$N_{\text {tension }}$ & 71 & 58 & 8 & 0 & & & & \\
\hline \multicolumn{9}{|l|}{ Type D } \\
\hline$\delta$ & $43.8(3.4)$ & $43.4(4.5)$ & $44.0(6.5)$ & $44.8(6.4)$ & $50.2(3.5)$ & $45.6(10.7)$ & $48.4(13.0)$ & $48.9(11.4)$ \\
\hline$L$ & $0.91(0.07)$ & $1.16(0.58)$ & $1.61(1.17)$ & $1.74(1.33)$ & $1.17(0.13)$ & $2.35(1.99)$ & $2.54(2.00)$ & $2.56(2.15)$ \\
\hline$d_{\max }$ & $0.27(0.04)$ & $0.28(0.05)$ & $0.46(0.35)$ & $0.52(0.43)$ & $0.28(0.04)$ & $0.51(0.23)$ & $0.63(0.48)$ & $0.52(0.22)$ \\
\hline$N$ & 4 & 6 & 14 & 16 & 6 & 13 & 16 & 19 \\
\hline$N_{\text {tension }}$ & - & - & - & - & & & & \\
\hline
\end{tabular}

tion, and only a very small number of tension cracks and shear fractures could develop in this experiment. Structures of both types only started to be macroscopically visible after $30 \%$ shortening. However, tension cracks were formed until $\sim 40 \%$ shortening and after that only shear fractures developed. The collapse of cracks gave rise to the formation of hybrid fractures (or mixed mode I-II fractures). They evolved to become shear fractures organised in two conjugate sets (Fig. 8a-c). With very few exceptions, shear fractures formed at angles of $\sim 40$ to $50^{\circ}$ with respect to $Z$ and tended to rotate towards $X$ at a rate significantly slower than a passive line (Fig. 7a, Table 4). At the end of the experiment, the length of fractures within the sampling area varied between 0.33 and $1.47 \mathrm{~cm}$, following an exponential distribution. The cumulative fracture slip was always less than $20 \%$ of the fracture length. Relatively variable maximum displacement $\left(d_{\max }\right)-$ length $(L)$ ratios could be found in this case (Fig. 9a).

The behaviour of model B, which was made of a mixture of soft plasticine and paper flakes, was significantly different. The presence of heterogeneities associated with flakes enhanced the nucleation of a large population of smallscale shear fractures (Fig. 5). Small tension cracks were also recognisable within the sample (Fig. 8d-f), although flakes prevented their propagation in a way that large cracks could not form. In this case, a large number of millimetrescale cracks formed at the interfaces between layers or between flakes and plasticine. Pinch-and-swell and boudinagelike structures also started to develop in the first deformation stages. Pinch-and-swell formed from heterogeneities in areas where layers were slightly thinner or thicker, or where microscopic cracks already existed. Boudinage-like structures de- 


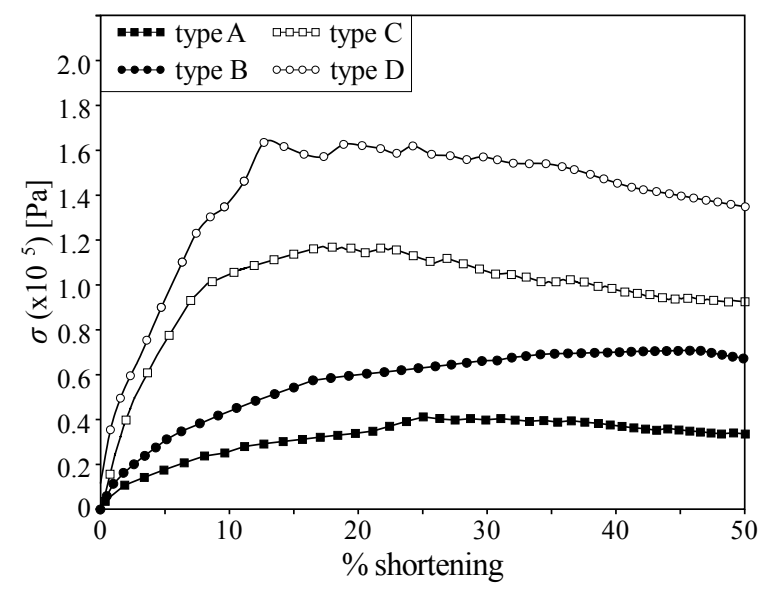

Figure 6. Stress vs. strain curves for the four multilayer experiments. Yielding followed by slight strain softening can be clearly identified for models $\mathrm{C}$ and $\mathrm{D}$, while experiments $\mathrm{A}$ and $\mathrm{B}$ record a progressive stress increase that tends towards steady state with increasing strain.

veloped when several tension cracks nucleated in the same layer. Two symmetrical sets of conjugate shear fractures formed in three different ways with increasing strain: (1) they directly nucleated (i.e. without precursors) enhanced by the heterogeneity of the two-phase (plasticine-paper flakes) system; (2) they formed by progressive necking of pinch-andswell and boudinage-like structures; and (3) they formed by coalescence and collapse of tension cracks (Fig. 8d-f). Shear fractures formed at an angle higher than $45^{\circ}$ with regard to the $Z$ axis (Fig. 7b). The percentage of fractures oriented at more than $45^{\circ}$ with $Z$ ranged between $88 \%$ at $20 \%$ shortening to more than $94 \%$ for $30-50 \%$ shortening, thus indicating that fractures slightly rotated towards $X$. Average orientations increased between $\sim 49$ and $56^{\circ}$ at 20 and $50 \%$ shortening respectively (Table 4 ). At the end of the experiment, shear-fracture lengths ranged between 0.5 and $1.9 \mathrm{~cm}$, and the cumulative fracture slip was approximately $25 \%$ of the total length. The ratio between maximum displacement $\left(d_{\max }\right)$ and length $(L)$ was considerably higher than that of model A (Fig. 9), even though fracture propagation was not very high in model B since new fractures nucleated all the time until the end of the experiment (see $N$ - total number of fractures per set in Table 4). At the model scale, deformation was approximately homogenously distributed, as evidenced by a strain localisation factor of $I_{\mathrm{loc}} \sim 1.16$ and shortening normal to the reference layers ranged between 47 and $54 \%$.

The evolution of model $\mathrm{C}$ resembles that of model $\mathrm{A}$ but with a considerably higher amount of fractures. In this case, strain localisation was related to the nucleation and growth of a very large population of relatively long tension cracks, which evolved to form two conjugate sets of shear fractures with increasing strain (Fig. 7c, Table 4). Tension cracks formed during the first experiment stages and up to $\sim 30 \%$ shortening. When deformation increased, their nucleation and propagation was aborted and they started to quickly collapse and rotate towards the extension direction, thus enhancing the formation of two conjugate sets of shear fractures. This process took place by crack collapse and coalescence and by fracture segment linkage (Fig. 8g, i). Such mechanisms enhanced fracture connectivity, thus amplifying the direct nucleation of secondary shear fractures. Boudinage-like structures did not develop in this experiment because tension cracks were not constrained to one layer but cut several consecutive layers. Fracture statistics illustrate the clear transition from a tension- to a shear-fracture-dominated system with progressive deformation. Almost no shear fractures were observed at $20 \%$ shortening, while many tension cracks developed. At $30 \%$ shortening there were still more tension than shear fractures, which were oriented at an average of $\sim 35^{\circ}$ with respect to $Z$ (with a standard deviation of $\sim 7^{\circ}$; Table 4). A marked change in the properties of the fracture network took place between 30 and $40 \%$ shortening. At $40 \%$ shortening only a few tension cracks remained active, while a dense network of shear fractures was observed. Such fractures had at this stage widely variable orientations with respect to $Z$ (from $\sim 25$ to $\sim 55^{\circ}$ ), with $43 \%$ of them oriented at angles higher than $45^{\circ}$. These variable orientations remained at $50 \%$ shortening, when all tension cracks have disappeared. At this stage $67 \%$ of shear fractures were oriented at more than $45^{\circ}$ with $Z$. Despite the differences in material behaviour and type of fractures, the ratio between fracture length and accumulated displacement was similar to the one observed for the type B model (Fig. 9). At the model scale, strain localisation by the fracture network was resolved at a length scale smaller than the sample length, since fractures did not cut across the entire experiment. The calculated normal shortening ranged between 45 and $55 \%$, and the strain localisation factor was therefore relatively low $\left(I_{\mathrm{loc}} \sim 1.2\right)$.

Finally, the stiffer model (type D) experienced a very different deformation history than the previous three experiments. Despite this, it presents some similarities with model $\mathrm{B}$, mainly associated with the presence of a second phase (i.e. paper flakes). Large tension cracks were not observed in model D (Fig. 5). Instead, a small number of very large shear fractures developed, with lengths ranging between 2.5 and $9 \mathrm{~cm}$. It is important to note that these measurements refer to individual fracture segments, but fracture zones composed of several segments were of course significantly longer than that. Some of them propagated up to the limits of the model and were able to accommodate considerably larger displacements than the ones registered in the other three experiments (Fig. 9). This observation is clearly supported by the fact that the maximum fracture displacement was approximately $40 \%$ of the total fracture length. Another special feature of this model is that the two conjugate shear-fracture sets were not symmetric, since the sinistral set nucleated earlier than the dextral one, which subsequently cross-cut and displaced the early sinistral fractures (Fig. 8j-1). Shear fractures in this 

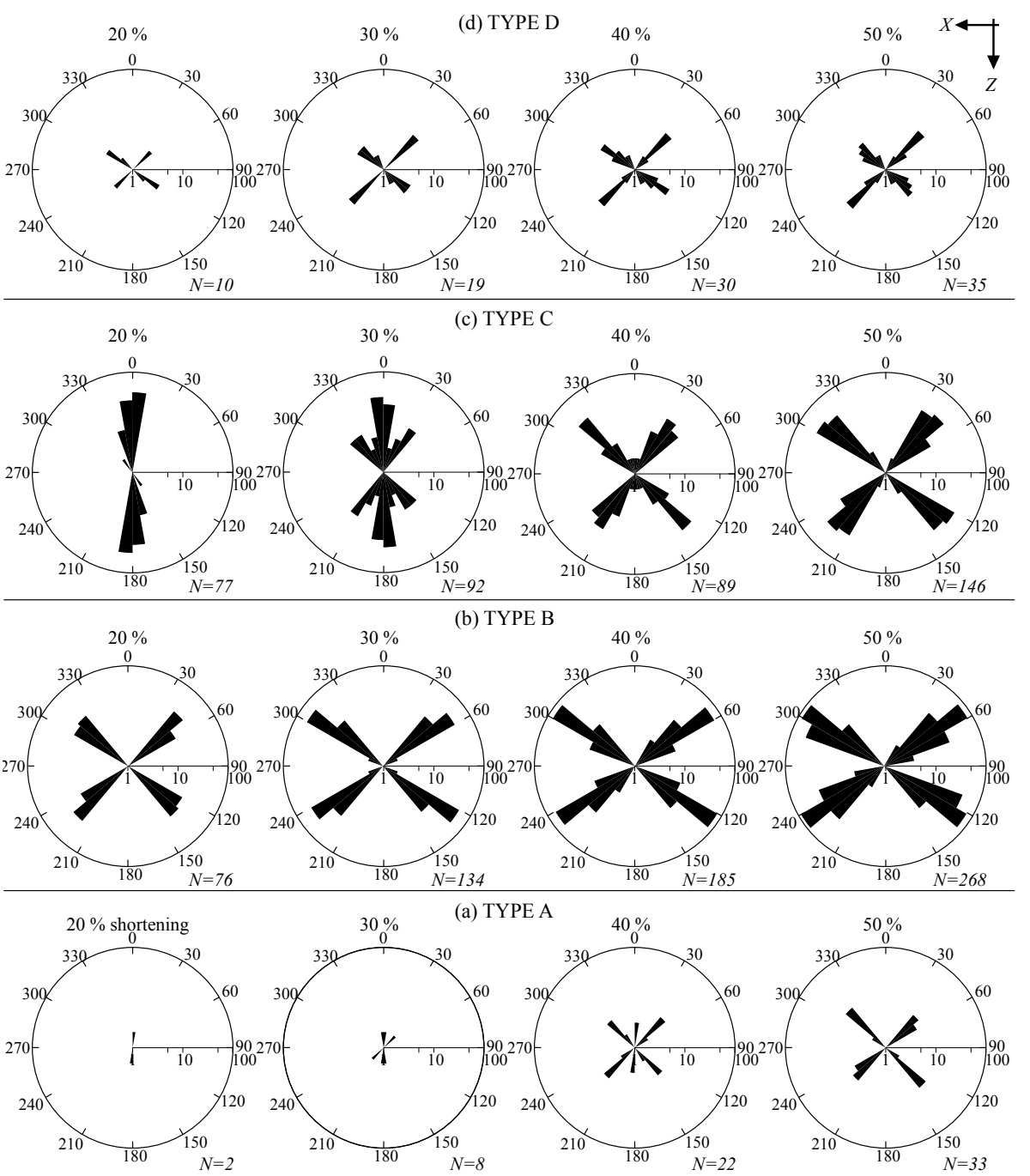

Figure 7. Rose diagrams showing the orientation and number of fractures (at orientation intervals of $10^{\circ}$ ) of experiments: (a) type A, (b) type $\mathrm{B}$, (c) type $\mathrm{C}$ and (d) type D. $N$ is the number of data measurements in each diagram. Only fractures measured within the sampling area are included. Note that horizontal scales are logarithmic.

model were, on average, oriented at 43 to $50^{\circ}$ with $Z$. However, these angles were very variable and some large fractures formed a lower angle with the maximum compression axis. Fractures in this model tended to accommodate deformation by slip, instead of rotating towards $X$ (Fig. 7d, Table 4), in a way contrary to the other three experiments in which the two sets were always symmetrical with respect to the $X$ and $Z$ axes. At the model scale, deformation was heterogeneously distributed and strong necking was observable at the central part of the experiment, where relative large shear fault zones cross-cut. A strong strain partitioning was detected between high and low strain domains, where layernormal shortening was about 63 and $30-36 \%$ respectively. The strain localisation factor $\left(I_{\mathrm{loc}}\right)$ was higher than 2.0.

\section{Discussion}

The experimental results obtained in this study indicate that the mechanical properties of an elastoviscoplastic material have a strong influence on the degree of brittle deformation and how deformation is accommodated by a fracture network (Figs. 5, 8). The style of developed structures and their properties strongly depend on the material mechanical behaviour (Figs. 7, 9, Table 4). A marked transition from distributed to strongly localised systems can be observed when variants of the same materials are deformed under the same conditions. Our experiments are made on two commercial types of plasticine (OCLU-PLAST and JOVI), which have a similar stress exponent when they are not mixed with other components (Table 1). The effective viscosity of pure JOVI plasticine is about 3 times higher than that of pure OCLU-PLAST, 

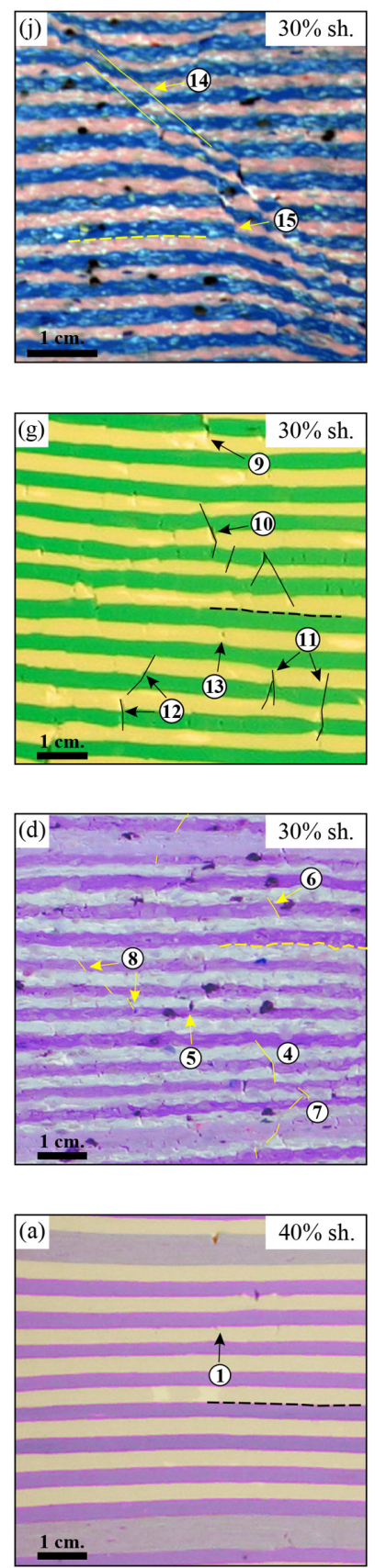

TYPE D

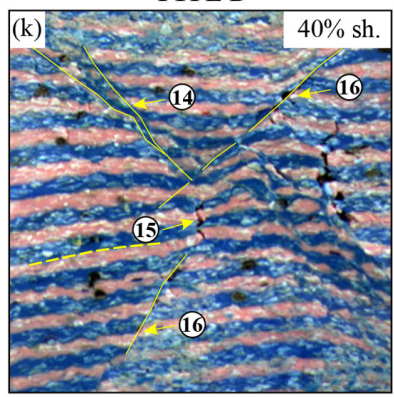

TYPE C

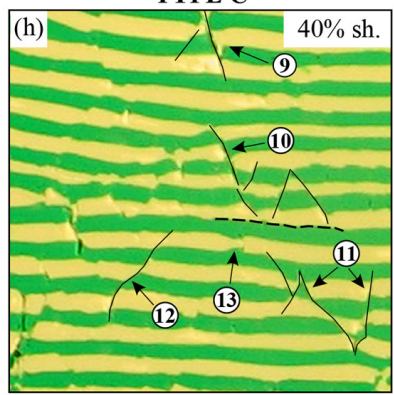

TYPE B

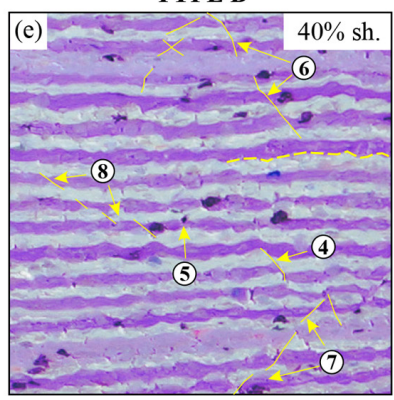

TYPE A

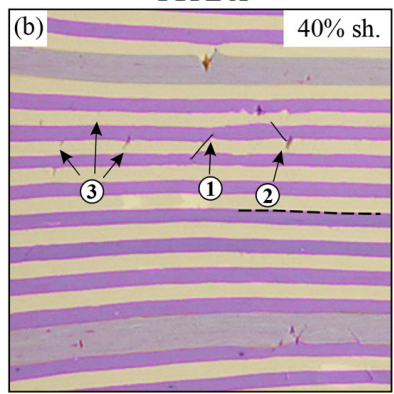

localised deformation
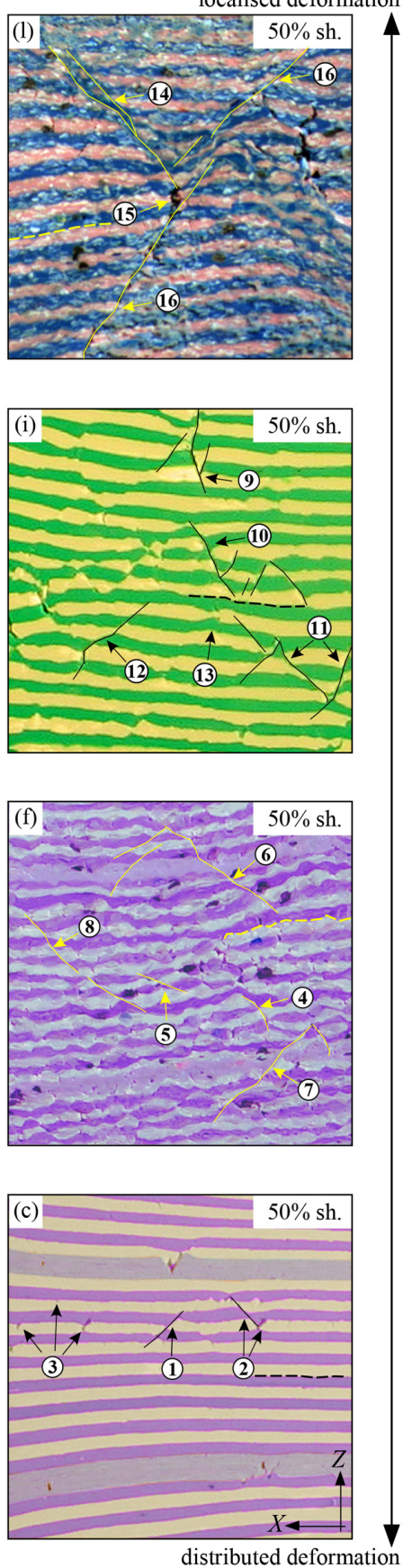

Figure 8. Detailed photographs showing the evolution of structures in the four different experiments. (a-c) Type A experiment: (1) a shearfracture forms from a slightly pinched layer; (2) coeval development of a tension crack and a shear fracture; (3) tension cracks keep forming until $\sim 40 \%$ shortening. (d-f) Type B experiment: (4) mixed-mode fracture with associated drag folds. The propagation rate was very low due to plastic deformation at fracture tips; (5) tension crack that collapsed and gave rise to a shear fracture; (6) in-plane shear fracture with enhanced propagation at one of the tips; $(7,8)$ linkage of fracture segments produced larger fractures with heterogeneous displacements. (g-i) Type C experiment: (9) nucleation and propagation of a tension crack that evolved to a mixed-shear mode fracture; (10) progressive enlargement of individual fractures as a result of progressive tip-line propagation and linkage with the nearest fracture segments; (11) nucleation of conjugate shear fractures from tension cracks, resulting in sharp fracture segments; (12) relatively long shear fracture that formed by linkage of a tension crack and a shear fracture; (13) small tension crack that evolved to form a heterogeneous asymmetric boudinage-like structure. (j-l) Type D experiment: (14) formation of two parallel dextral fractures that propagate and join, and their lower tip ends at a larger conjugate fracture; (15) development of a tension crack at the intersection between large shear fractures; (16) a very large sinistral fracture with zigzag geometry forms by segment linkage from side to side of the model. Solid lines represent fractures, while dashed lines indicate layering. 

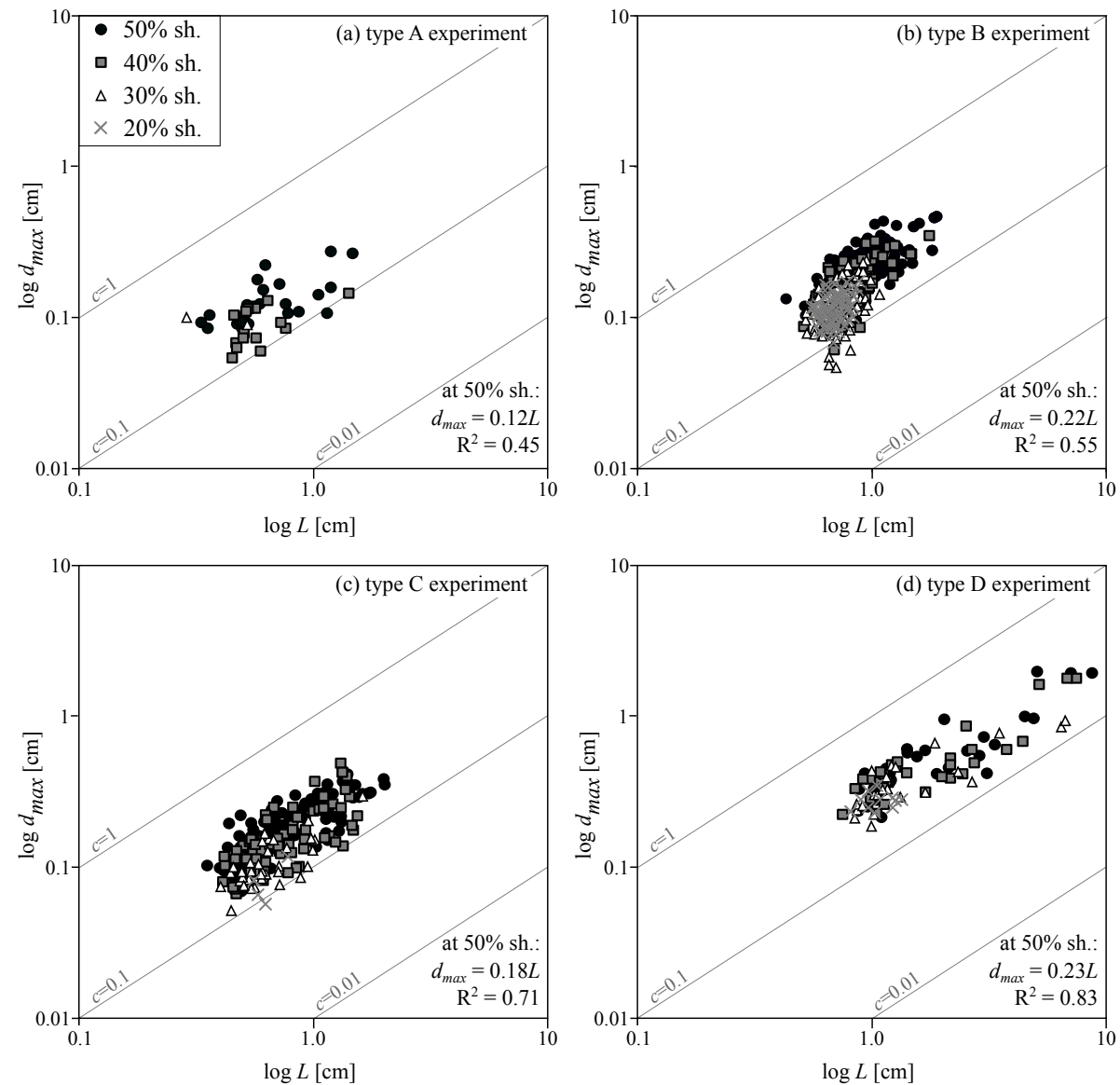

Figure 9. Log maximum fracture length $\left(d_{\max }\right)$ vs. log maximum fracture displacement $(L)$ graphs for models (a) type A, (b) type B, (c) type $\mathrm{C}$ and (d) type D. Data correspond to shear fractures measured at 20, 30, 40 and 50\% of shortening within the sampling area. Grey lines indicate linear relationships in the $\log -\log$ graph for different $c$ values in Eq. (2).

while elastic shear modulus $(G)$ values of mixtures made of JOVI plasticine are between 2 and 6 times higher than those made of OCLU-PLAST (Table 2). These variations are already high enough to result in two very different deformation systems, since model A (made of pure OCLU-PLAST plasticine) mostly accommodated deformation by homogeneous flattening associated with viscous flow while a dense network of tension and shear fractures coeval with ductile flow developed in model C (made of pure JOVI plasticine). The stronger elastoviscous behaviour of type $\mathrm{C}$ plasticine does not allow an efficient stress relaxation by viscous flow, even for high deformation values (> $25 \%$ shortening), thus enhancing fracture formation. The addition of paper flakes as a second phase, statistically oriented parallel to layering in the initial model, produced again a remarkably different mechanical behaviour. A dense network of small shear fractures formed in model B (made of OCLU-PLAST plasticine and flakes), while a few large fractures controlling the system developed in the most rigid experiment (model D, made of JOVI plasticine and paper flakes).
As explained in Sect. 2.3, no shear bands or fractures formed in the uniaxial compression tests. This is evidenced by the lack of material discontinuities and the absence of pronounced and sharp yield points in the stress-strain curves (Fig. 3). This applies not only to tests made of pure plasticine but also to tests composed of mixtures B and D, which include randomly oriented paper flakes. These observations suggest that the presence of heterogeneities within the material is required to produce fracture onset at relatively low deformation stages (less than $20 \%$ shortening). In our experiments, heterogeneities are associated with two types of transverse anisotropy: (1) composite anisotropy (Treagus, 1997) defined by stacking of layers with slight contrasting properties and (2) intrinsic anisotropy produced by the preferred orientation of elements of a second phase (i.e. paper flakes) statistically oriented parallel to layering. All experiments are composites, but models B and D include an additional intrinsic anisotropy. The type and degree of anisotropy (composite vs. intrinsic) can play a fundamental role on the resulting structures and the bulk material behaviour (Griera et al., 2011, 2013). 
The transition from ductile to coeval ductile-brittle behaviour is determined by the ability of the material to dissipate the imposed external work and relax the elastic strain energy stored as a consequence of loading (e.g. Anderson, 2005). This relaxation can take place either by viscous or coeval viscous-brittle deformation. New fractures can only grow when the strain energy released during fracture growth exceeds the sum of the surface energy of the new crack segment and the plastic deformation energy at the crack tip (e.g. Perez, 2004). These processes strongly depend on the material strength. Stress-strain curves are used to establish a qualitative relationship between the strain localisation pattern and the work necessary to deform the sample. Such curves reveal a higher degree of localisation in the harder model (type D), which registered a marked strain softening behaviour following the stress peak ( $\sim 12 \%$ shortening) (Fig. 6). The localisation of fracture networks is related to a reduction of the active volume that is being deformed and an increase on the efficiency of the accommodation of the imposed shortening by fracture slip. The growth of a network of a few large fractures in the most viscous model (type D), or the development of a well arranged but segmented fracture network in experiment $\mathrm{C}$, results in strain softening after yielding (Figs. 5, 6). Fracture networks in these two models were able to accommodate the displacement imposed by the boundary conditions, although experiment $\mathrm{C}$ also deformed coevally by dominant viscous flow. Model A basically deformed by viscous flow, and the resulting stress-strain curve displays first a slight increase, and then a steady-state flow with gentle strain softening after $\sim 25 \%$ shortening. Contrarily, model B evolved by coeval small-scale fracturing and viscous flow. Deformation was distributed in a large population of small shear fractures with low propagation rates. Viscous relaxation was able to soften the increase of stress and inhibit the propagation of large faults in this case, and the stress-strain curve thus registered a very slight hardening associated with steady-state flow.

When loading started, ductile deformation was dominant in all models and macroscopic fractures only began to nucleate after $15-20 \%$ shortening. The type of early structures strongly depends on whether the anisotropy is only composite (modes A and C) or composite plus intrinsic (models B and D). In composite anisotropic experiments, the first developed structures were pinch-and-swell and relatively large tension cracks that evolved to mixed-mode and shear fractures when fault planes rotated towards the extensional direction or when cracks collapsed and coalesced (Figs. 7, 8a-c). Shear fractures in these cases are oriented at $\sim 45^{\circ}$ with regard to the maximum compression axis $Z$. Schmalholz and Maeder (2012) suggested that pinch-and-swell structures can develop in materials with power-law rheologies and low viscosity ratios and showed with numerical simulations how conjugate shear zones can nucleate from such precursors. The presence of hard flakes prevented the propagation of large tension cracks in composite-intrinsic experiments but enhanced the nucleation of numerous small ones. Their fast collapse favours the formation of a conjugate shear-fracture network oriented at relative high angles from the maximum compressive stress. Very small cracks were visible in model B but they were not the only precursors of shear fractures, since the latter could also nucleate directly from heterogeneities associated with the presence of flakes. Not many tension cracks were observed in model $\mathrm{D}$, suggesting that this material accumulated stresses until brittle yielding was reached and then relatively large shear fractures directly nucleated. Tension cracks are related to low effective confining pressure and low differential stress conditions, which enhance the presence of tensional stresses. Such cracks stop nucleating in these models when viscous flow and/or slip along the shear-fracture network are more efficient in dissipating the applied stress. Gomez-Rivas and Griera (2011) presented experiments with the model A configuration, but performed at different strain rates, and found that tension cracks can form until the end of the experiment if the strain rate is high enough $\left(10^{-4} \mathrm{~s}^{-1}\right)$. This is an indication that the strain rate at which we performed our experiments allows a transition from extensional- to shear-fracture-dominated systems with progressive deformation.

The collapse and coalescence of tension cracks formed as a result of local layer-perpendicular extension or by cavitation processes (Bons et al., 2004, 2008, 2010; Arslan et al., 2008; Rybacki et al., 2008; Fusseis et al., 2009) can result in the development of shear fractures in middle- and lower-crust rocks. A key question here is how the development of cracks and open voids in our models scales to nature, since these experiments have been run under low confining pressure conditions and in the absence of fluids. Rybacki et al. (2008) suggested that cavitation processes in natural shear zones might not only be related to high pore fluid pressures but also depend on local stress concentrations and strain compatibility problems at grain boundaries, triple junctions and matrix/particle interfaces. In the case of our experiments, heterogeneities associated with the presence of paper flakes and layer interfaces are probably causing local problems in maintaining strain compatibility and therefore enhance crack opening. Figure 8 illustrates how shear fractures form as a consequence of single crack collapse (structures 1 and 5), rotation of a single tension crack (structures 2 and 9), coalescence and linkage of several cracks (structures 11 and 12), direct nucleation from small-scale heterogeneities (structures 6,14 and 15) or linkage of pre-existing mixed-mode or shear fractures (structures $7,8,10,12,14$ and 15 ). The variety of fracture formation mechanisms indicates that caution has to be taken when using failure criteria to predict fracture formation in ductile and anisotropic rocks. However, in spite of the complex localisation mechanisms, most shear fractures form at orientations close to $45^{\circ}$ with regard to $Z$, as predicted by the Tresca criterion (e.g. Twiss and Moores, 1992) in models A, C and D. This implies that shear fractures develop in the same orientation as the maxi- 
mum shear stress, which is evidence for a very low frictional behaviour of plasticine. However, when intrinsic anisotropy is present and the material is relatively soft (i.e. model B), shear fractures form at an angle higher than $45^{\circ}$ with $Z$. This phenomenon has been observed in a variety of field and experimental studies, in which the principal compressive stress $\sigma_{1}$ is parallel to the obtuse bisector between conjugate shear band or shear-fracture sets (e.g. Cobbold et al., 1971; Platt and Vissers, 1980; Berhmann, 1987; Harris and Cobbold, 1984; Hanmer et al., 1996; Kidan and Cosgrove, 1996; Mancktelow and Pennacchioni, 2005; Gomez-Rivas et al., 2007; Pennacchioni and Mancktelow, 2007; GomezRivas and Griera, 2012). Such large angles can be related to a variety of factors, including fracture rotation towards the extension direction, re-activation of pre-existing structures (especially when they are frictionally weak surfaces), cataclastic grain size reduction or pressure-driven processes. Since some of these processes do not operate in our models, we consider that the high dihedral angles in our experiment $\mathrm{B}$ are associated with the almost absent frictional behaviour of plasticine (e.g. McClay, 1976; Zulauf and Zulauf, 2004) combined with low fracture propagation due to dominant viscous flow and presence of planar heterogeneities (as in the experiments presented in Gomez-Rivas and Griera, 2012).

As demonstrated by average fracture lengths $(L)$ and number of fractures per set $(N)$ in Table 4, fracture propagation and connectivity are low in models A, B and C, while they are relatively higher in model $\mathrm{D}$. Both conjugate sets of shear fractures have similar lengths, displacements and a symmetric arrangement with respect to the compression axis in experiments A, B and C (Figs. 5, 7, 9). This is coherent with the imposed coaxial deformation conditions and a symmetrical orientation of layers with regard to the principal stress axes $Z$ and $X$. In these experiments large fractures crosscutting the entire model did not develop. Although stresses were high enough to activate the onset of brittle tensile and shear fractures, the high material toughness reduced the ability of fractures to propagate, making it easier for them to grow by linkage and dissipate imposed stresses by nucleation of new fractures rather than propagating existing ones. Contrarily, the stiffer experiment (model D) did not display a symmetric distribution of both sets of fractures. In this case the dextral shear sense array is predominant over the sinistral one, despite the coaxial boundary conditions and the initial orientation of layers parallel to $X$. A strong strain partitioning between low and high strain bands can be observed in this model. Large fracture zones cross-cutting the model dominate deformation in this experiment. They accommodate the imposed deformation and prevent the growth of a small-scale conjugate shear-fracture network. The formation of large fractures controlling the system is related to a release of the stored elastic energy during crack growth (e.g. Perez, 2004) and an associated increase of their growth rate. This can be explained by the higher stiffness and viscoelastic behaviour of the material that require longer times to relax elastic stresses by viscous flow. The large stored elastic energy during the shear fractures onset is probably the driving force that can explain the relative higher fracture propagation rates in this experiment and therefore the associated development of a few long fractures.

Experimental observations show that fracture growth is a consequence of a combination of fault tip propagation with slip increase and segmentation linkage (Walsh et al., 2002). The strength of the deforming material partially controls the ratio between the maximum displacement of each fault $\left(d_{\max }\right)$ and its length $(L)$. The relationship between these two parameters depends on the fault displacement, expressed in the parameter $c$, and an exponent $m$ (Kim and Sanderson, 2005):

$d_{\max }=c L^{m}$.

This relationship in our models is approximately linear in a $\log -\log$ graph, although the limited data range prevents extrapolating these data to larger scales. The $d_{\max } / L$ ratios observed in this series of experiments range between 0.12 and 0.23 (Fig. 9) and are therefore higher than the ones inferred from natural faults, which vary between $\sim 10^{-2}$ and $\sim 10^{-4}$; e.g. Kim and Sanderson, 2005). There is a progressive increase in the $d_{\max } / L$ ratio when the material strength is raised, systematically from model A (softer) to model D (tougher). Gomez-Rivas and Griera (2011) also reported that strain rate increases the displacement/length relationship. Such relationships in our experiments are considerably higher than in other cases previously reported in the literature (e.g. Kim and Sanderson, 2005 and references therein), mostly from brittle rocks. However, Grasemann et al. (2011) found similar values in small-scale fractures associated with flanking folds within a low-grade ductile shear zone. This suggests that fault displacement-length relationships are probably higher in rocks that undergo dominant ductile deformation. Since shear fractures in our experiments are easy slip zones (i.e. weak faults) and do not normally heal, a significant amount of deformation can be accommodated by displacement along fractures, especially in the harder models. However, the high material toughness prevents fractures from propagating, thus resulting in relatively high $d_{\max } / L$ values. Fracture propagation requires the release of a certain amount of energy at crack tips, which are areas of strain hardening. The dominant viscous deformation of models A, B and C does not allow enough energy accumulation at crack tips for propagation. On the contrary, such energy is high enough in model $\mathrm{D}$, where fractures could grow.

The results of the experiments presented in this study contribute to the understanding of the main controls on fracture localisation in ductile materials as well as the accommodation of deformation by different fracture networks depending on the rock mechanical properties. These models illustrate how strain localisation processes operate in a dominant ductile regime and allow visualising the transition from brittle to ductile behaviour using materials with a similar rheology. 
The progressive onset, interaction and evolution of different types of structures (tension cracks, pinch-and-swell, hybrid fractures, shear fractures) define a progressive change in the behaviour of the system. The presence of composite or combined composite-intrinsic transverse anisotropy plays a fundamental role, since it enhances brittle behaviour, promoting fracture formation and helping to dissipate the applied stress.

\section{Conclusions}

This contribution presents an experimental study on the influence of material strength on the formation of fracture networks in materials that are deformed by dominant viscous flow. Four plasticine multilayers, made of different mixtures, were deformed under coaxial boundary conditions at a constant strain rate and temperature. The following main conclusions arise from these experiments:

1. The increase of material strength causes a progressive transition from a non-localising end member, where deformation is mostly accommodated by homogeneous flattening, to a strongly localised system where a few fractures accommodate displacement. This ductile-tobrittle transition is controlled by the ability of the material to dissipate the external work and relax the elastic strain during loading, either by viscous flow or coeval flow and failure. Shear fractures, which are oriented at $\sim 45^{\circ}$ from $\sigma_{1}$ in most experiments, form through the collapse and coalescence of tension cracks, the evolution of pinch-and-swell structures or by direct nucleation associated with heterogeneities.

2. Stress-strain curves record the progressive transition from ductile-dominated to fracture-dominated systems. Models deformed by dominant viscous flow are characterised by the absence of yield points and a slight stress increase followed by steady state behaviour. Contrarily, localising systems record higher stress magnitudes and clear yield points followed by subsequent strain softening associated with deformation accommodated by fractures.

3. Additional intrinsic anisotropy, resulting from the presence of paper flakes statistically oriented parallel to layers, produces a change in the deformation behaviour inhibiting the nucleation of tension cracks. Enhanced transverse anisotropy in the soft model reduces fracture propagation and favours the formation a dense network of small-scale shear fractures oriented at high angles $\left(>45^{\circ}\right)$ with $\sigma_{1}$. Contrarily, flakes significantly increase the rigidity of the material when added to the harder plasticine and promote the formation of an asymmetric arrangement of a reduced number of large fractures controlling the system.

4. Material strength increases the fracture maximum displacement $\left(d_{\max }\right)$ to length $(L)$ ratios. Such values are relatively high compared to those resulting from fractures formed in elastic-brittle media. This is associated with the low propagation rates of fractures in rocks undergoing ductile deformation and also with the presence of anisotropy.

Acknowledgements. This work was financed through the research project CGL2004-03657, funded by the Spanish Ministry of Education and Science. We thank J. Carreras, E. Druguet and L. M. Castaño for discussions on some aspects related to this work. We gratefully acknowledge G. Zulauf and T. Duretz, whose constructive reviews greatly improved the manuscript, and the editorial guidance of $\mathrm{N}$. Mancktelow.

Special Issue: "Deformation mechanisms and ductile strain localization in the lithosphere"

Edited by: L. Menegon, G. Pennacchioni, M. Stipp, N. Mancktelow, and R. Law

\section{References}

Anderson, T. L.: Fracture mechanics: fundamentals and applications, 3rd Edition, CRC Press Taylor \& Francis, 640 pp., 2005.

Arslan, A., Passchier, C. W., and Koehn, D.: Foliation boudinage, J. Struct. Geol., 30, 291-309, 2008.

Behrmann, J. H.: A precautionary note on shear bands as kinematic indicators, J. Struct. Geol., 9, 659-666, 1987.

Bons, P. D., Druguet, E., Hamann, I., Carreras, J., and Passchier, C. W.: Apparent boudinage in dykes, J. Struct. Geol., 26, 625-636, 2004.

Bons, P. D., Druguet, E., Castaño, L. M., and Elburg, M. A.: Finding what is not there anymore: recognizing missing fluid and magma volumes, Geology, 36, 851-854, 2008.

Bons, P. D., Becker, J. K., Elburg, M. A., and Urtson, K.: Granite formation: Stepwise accumulation of melt or connected networks?, Earth. Env. Sci. T. R. So., 100, 105-115, 2010.

Carreras, J., Julivert, M., Soldevila, A., Griera, A., and Soler, D.: A deformation stage for analogue modelling of structures developed under variable degree of non-coaxiality, in: Geoscience 2000 Abstracts volume, University of Manchester, section Modelling in Structural Geology, 126, 2000.

Cobbold, P. R., Cosgrove, J. W., and Summers, J. M.: Development of internal structures in deformed anisotropic rocks, Tectonophysics, 12, 23-53, 1971.

Davidson, C., Schmid, S. M., and Hollister, L. S.: Role of melt during deformation in the deep crust, Terra Nova, 6, 133-142, 1994.

Druguet, E. and Carreras, J.: Analogue modelling of syntectonic leucosomes in migmatitic schists, J. Struct. Geol., 28, 17341747, 2006.

Druguet, E. and Castaño, L. M.: Analysis of syntectonic magmatic veins at the mesoscale, J. Geol. Soc. India, 75, 60-73, 2010.

Exner, U., Mancktelow, N. S., and Grasemann, B.: Progressive development of s-type flanking folds in simple shear, J. Struct. Geol., 26, 2191-2201, 2004. 
Fagereng, Å.: On stress and strain in a continuous-discontinuous shear zone undergoing simple shear and volume loss, J. Struct. Geol., 50, 44-53, 2013.

Fusseis, F., Handy, M. R., and Schrank, C.: Networking of shear zones at the brittle-to-viscous transition (Cap de Creus, NE Spain), J. Struct. Geol., 28, 1228-1243, 2006.

Fusseis, F., Regenauer-Lieb, K., Liu, J., Hough, R. M., and De Carlo, F.: Creep cavitation can establish a dynamic granular fluid pump in ductile shear zones, Nature, 459, 974-977, 2009.

Gomez-Rivas, E.: Localización de deformación en medios dúctiles y anisótropos: estudio de campo, experimental y numérico, Ph.D. thesis, Universitat Autònoma de Barceloma, 247 pp, available at: http://www.tesisenxarxa.net/TDX-1120108-151236/ (last access: 11 May 2015), 2008.

Gomez-Rivas, E. and Griera, A.: Influence of mechanical anisotropy on shear fracture development, Trab. Geol., 29, 305$311,2009$.

Gomez-Rivas, E. and Griera, A.: Strain rate influence on fracture development in experimental ductile multilayers, Tectonophysics, 502, 351-363, 2011.

Gomez-Rivas, E. and Griera, A.: Shear fractures in anisotropic ductile materials: an experimental approach, J. Struct. Geol., 34, 61$76,2012$.

Gomez-Rivas, E., Bons, P. D., Griera, A., Carreras, J., Druguet, E., and Evans, L.: Strain and vorticity analysis using small-scale faults and associated drag folds, J. Struct. Geol., 29, 1882-1899, 2007.

Grasemann, B., Exner, U., and Tschegg, C.: Displacement-length scaling of brittle faults in ductile shear, J. Struct. Geol., 33, 1650 1661,2011

Griera, A., Bons, P. D., Jessell, M. W., Lebensohn, R. A., Evans, L., and Gomez-Rivas, E.: Strain localization and porphyroclast rotation, Geology, 39, 275-278, 2011.

Griera, A., Llorens, M.-G., Gomez-Rivas, E., Bons, P. D., Jessell, M. W., Evans, L. A., and Lebensohn, R.: Numerical modelling of porphyroclast and porphyroblast rotation in anisotropic rocks, Tectonophysics, 587, 4-29, 2013.

Guermani, A. and Pennacchioni, G.: Brittle precursors of plastic deformation in a granite: an example from the Mont Blanc Massif (Helvetic, Western Alps), J. Struct. Geol., 20, 135-148, 1998.

Hanmer, S., Corrigan, D., and Ganas, A.: Orientation of nucleating faults in anisotropic media: insights from three-dimensional deformation experiments, Tectonophysics, 267, 275-290, 1996.

Harris, L. B. and Cobbold, P. R.: Development of conjugate shear bands during bulk simple shearing, J. Struct. Geol., 7, 37-44, 1985.

Hobbs, B. E., Ord, A., and Teyssier, C.: Earthquakes in the ductile regime?, Pure Appl. Geophys., 124, 309-336, 1986.

Kidan, T. W. and Cosgrove, J. W.: The deformation of multilayers by layer-normal compression: an experimental investigation, J. Struct. Geol., 18, 461-474, 1996.

Kim, Y.-S. and Sanderson, D. J.: The relationship between displacement and length of faults: a review, Earth-Sci. Rev., 68, 317-334, 2005

Kocher, T. and Mancktelow, N. S.: Dynamic reverse modelling of flanking structures: a source of quantitative kinematic information, J. Struct. Geol., 27, 1346-1354, 2005.
Kocher, T. and Mancktelow, N. S.: Flanking structure development in anisotropic viscous rock, J. Struct. Geol., 28, 1139-1145, 2006.

Mancktelow, N. S.: The rheology of paraffin wax and its usefulness as an analogue for rocks, Bull. Geol. Institutions Univ. Uppsala, 14, 181-193, 1988

Mancktelow, N. S.: How ductile are ductile shear zones?, Geology, 34, 345-348, 2006.

Mancktelow, N. S.: Interaction between brittle fracture and ductile flow during crustal deformation, B. Soc. Geol. Ital., 127, 217220, 2008

Mancktelow, N. S. and Pennacchioni, G.: The control of precursor brittle fracture and fluid-rock interaction on the development of single and paired ductile shear zones, J. Struct. Geol., 27, 645661,2005

Mancktelow, N. S.: Fracture and flow in natural rock deformation, Trabajos de Geología, 29, 29-35, 2009.

Mandl, G.: Faulting in Brittle Rocks, Springer-Verlag, BerlinHeidelberg-New York, 434 pp., 2000.

McClay, K. R.: The rheology of plasticine, Tectonophysics, 33, T7$\mathrm{T} 15,1976$

Misra, S., Mandal, N., Dhar, R., and Chakraborty, C.: Mechanisms of deformation localization at the tips of shear fractures: Findings from analogue experiments and field evidence, J. Geophys. Res., 114, B04204, doi:10.1029/2008JB005737, 2009,

Passchier, C. W.: The generation of ductile and brittle shear bands in a low-angle mylonite zone, J. Struct. Geol., 6, 273-281, 1984.

Passchier, C. W.: Flanking structures, J. Struct. Geol., 23, 951-962, 2001

Paterson, M. S.: Experimental rock deformation: the brittle field, 2nd Edition, Springer-Verlag, Berlin, Germany, 1978.

Pennacchioni, G.: Control of the geometry of precursor brittle structures on the type of ductile shear zone in the Adamello tonalites, Southern Alps (Italy), J. Struct. Geol., 27, 627-644, 2005.

Pennacchioni, G. and Cesare, B.: Ductile-brittle transition in preAlpine amphibolite facies mylonites during evolution from water-present to water-deficient conditions (Mont Mary Nappe, Italian Western Alps), J. Metamorph. Geol., 15, 777-791, 1997.

Pennacchioni, G. and Mancktelow, N. S.: Nucleation and initial growth of a shear zone network within compositionally and structurally heterogeneous granitoids under amphibolite facies conditions, J. Struct. Geol., 29, 1757-1780, 2007.

Perez, N.: Fracture Mechanics, 284 pp., ISBN 978-1-4020-7861-3, Springer, New York, USA, 2004

Pfiffner, O. and Ramsay, J.: Constraints on geological strain rates: arguments from finite strain states of naturally deformed rocks, J. Geophys. Res.-Sol. Ea., 87, 311-321, 1982.

Platt, J. P. and Vissers, R. L. M.: Extensional structures in anisotropic rocks, J. Struct. Geol., 2, 397-410, 1980.

Poliakov, A. N. B., Cundall, P. A., Podladchikov, Y. Y., and Lyakhovsky, V. A.: An explicit inertial method for the simulation of viscoelastic flow: an evaluation of elastic effects on diapiric flow in two- and three-layers models, in: Flow and Creep in the Solar System: Observations, Modeling and Theory, edited by: Stone, D. B. and Runcorn, S. K., Kluwer Academic Publishers, Dordrecht, the Netherlands, 175-195, 1993.

Ramberg, H.: Gravity, Deformation and the Earth's Crust, Academic Press, London, UK, 214 pp., 1981. 
Ranalli, G.: Rheology of the Earth, Chapman \& Hall, London, UK, 414 pp., 1995.

Reiner, M.: The Deborah Number, Physics Today, 17, p. 62, 1964.

Rybacki, E., Wirth, R., and Dresen, G.: High-strain creep of feldspar rocks: Implications for cavitation and ductile failure in the lower crust, Geophys. Res. Lett., 35, L04304, doi:10.1029/2007GL032478, 2008.

Schmalholz, S. M. and Maeder, X.: Pinch-and-swell structure and shear zones in viscoplastic layers, J. Struct. Geol., 37, 75-88, 2012.

Schöpfer, M. and Zulauf, G.: Strain-dependent rheology and the memory of plasticine, Tectonophysics, 354, 85-99, 2002.

Segall, P. and Simpson, C.: Nucleation of ductile shear zones on dilatant fractures, Geology, 14, 56-59, 1986.

Simpson, C.: Deformation of granitic rocks across the brittle-ductile transition. J. Struct. Geol., 7, 503-511, 1985.

Smithson, S. B.: Densities of metamorphic rocks, Geophysics, 36, 690-694, 1971.

Talbot, C. J.: Can field data constrain rock viscosities?, J. Struct. Geol., 21, 949-957, 1999.
Treagus, S. H.: Deformation partitioning in folds: implications for fold geometry and cleavage patterns, in: Evolution of Geological Structures in Micro- to Macro-Scales, edited by: Sengupta, S., Chapman \& Hall, London, UK, 341-372, 1997.

Twiss, R. J. and Moores, E. M.: Structural Geology, W. H. Freeman, New York, USA, 544 pp., 1992.

Walsh, J. J. and Watterson, J.: Distributions of cumulative displacement and seismic slip on a single normal fault surface, J. Struct. Geol., 9, 1039-1046, 1987.

Walsh, J. J., Nicol, A., and Childs, C.: An alternative model for the growth of faults, J. Struct. Geol., 24, 1669-1675, 2002.

Weijermars, R.: Principles of rock mechanics, Alboran Science Publishing, Amsterdam, the Netherlands, 359 pp., 1997.

Weijermars, R. and Schmeling, H.: Scaling of Newtonian and nonNewtonian fluid dynamics without inertia for quantitative modelling of rock flow due to gravity (including the concept of rheological similarity), Phys. Earth Planet. In., 43, 316-330, 1986.

Zulauf, J. and Zulauf, G.: Rheology of plasticine used as rock analogue: the impact of temperature, composition and strain, J. Struct. Geol., 26, 725-737, 2004. 